WSRC-MS-92-379

\title{
THE LEGACY OF Cf-252 OPERATIONS AT SAVANNAH RIVER TECHNOLOGY CENTER: CONTINUOUS RELEASES OF RADIOIODINE TO THE ATMOSPHERE (U)
}

by

M. V. Kantelo

WSRC-MS--92-379

Savannah River Site

DE93 011788

Aiken, South Carolina 29808

B. S. Crandall

A document prepared for:

Spring Meeting Canberra/Nuclear Data

at San Diego, CA

from 04/28/93 thru 04/30/93

DOE Contract No.

This paper was prepared in connection with work done under the above contract number with the U.S.

Department of Energy. By acceptance of this paper, the publisher and/or recipient acknowledges the U. S.

Government's right to retain a nonexclusive, royalty-free license in and to any copyright covering this paper, along with the right to reproduce and to authorize others to reproduce all or part of the copyrighted paper. 


\section{DISCLAIMER}

This report was prepared as an account of work sponsored by an agency of the United States Government. Neither the United States Government nor any agency thereof, nor any of their employees, makes any warranty, express or implied, or assumes any legal liability or responsibility for the accuracy, completeness, or usefulness of any information, apparatus, product, or process disclosed, or represents that its use would not infringe privately owned rights. Reference herein to any specific commercial product, process, or service by trade name, trademark, manufacturer, or otherwise does not necessarily constitute or imply its endorsement, recommendation, or favoring by the United States Government or any agency thereof. The views and opinions of authors expressed herein do not necessarily state or reflect those of the United States Government or any agency thereof.

This report has been reproduced directly from the best available copy.

Available to DOE and DOE contractors from the Office of Scientific and Technical Information, P.O. Box 62, Oak Ridge, TN 37831; prices available from (615) 576-8401, FTS 626-8401.

Available to the public from the National Technical Information Service, U.S. Department of Commerce, 5285 Port Royal Rd., Springfield, VA 22161. 


\section{EXECUTIVE SUMMARY}

The iodine isotopes I-132, I-133, I-134, and I-135, which have half-lives ranging from 53 minites to 21 hours, are measured in the atmospheric effluent from the Savannah River Technology Center (SRTC) at the Savannah River Site (SRS) near Aiken, South Carolina. SRS is operated by Westinghouse Savannah River Company for the U.S. Department of Energy (DOE).

The isotopes' release rates range from 10 to 300 microcuries per week compared to the rate of 0.7 microcuries per week routinely measured for I-131. The resulting annual dose from all iodine isotopes is minor; it comprises 0.01 percent of the total offsite dose due to atmospheric releases from SRS in 1990.

Circumstantial evidence indicates the radioiodine originates from traces of unencapsulated Cf- 252. The determination that spontaneous fission of $\mathrm{Cf}-252$ is the source of the radioiodine has several ramifications.

- Radioactive fission-product isotopes of the noble gas elements krypton and xenon must also be released. Noble gases are more volatile and mobile than iodine. Also, the released iodine isotopes decay to xenon isotopes.

- The noble gases decay tc non-gaseous elements that are transported along with radioiodine to the tel, $t$ strial environment by deposition from the SRTC plume. Only Sr-89 is helieved to Iccumulate sufficiently in the environment to approach deteciable levels.

- Given similar conditions in earlier years, releases of short-lived radioiodine have occurred undeterte $c$ in routiue monitoring since the early 1970 s. Release rates 20 years ago would have been 200 times greater than current release rates.

This report documents preliminary experiments conducted by SRTC and Environmental Monitoring Section (EMS) scientists. The release process and the environmental impact of fission products from Cf- 252 should be thoroughly researched.

\section{SUMMARY}

SRTC continues to release I-131 to the atmosphere long after such releases from reactors and separations facilities at SRS have diminished or ceased. Special measurements of the air discharged from the SRTC sandfilter during October 1991 reveal that the short-lived iodine isotopes I-132, I-133, I-134, and I-135 are released at rates that range from 10 to 300 microcuries per week. The release rate of I-131 is 0.7 microcuries per week.

The dose from the releases is minor. The annual dose to the maximally exposed individual from all iodine isotopes is 0.01 percent of the total offsite dose due to all radionuclides released to the atmo-

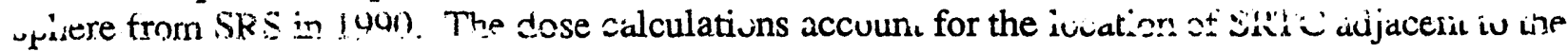
site perimeter.

The scientists' interpretation of the current releases is that the radioiodine originates from Cf-252, which decays by spontaneous fission and in turn produces the isotopes I-131 through I-135. Volatile chemical forms of iodine diffuse to the laboratory exhaust system from Cf-252 that is not encapsu- 
lated. As little as 4 micrograms of unencapsulated $\mathrm{Cf}-252$ can release the quartities of radioiodine detected.

Analysis of historical release data reveals that the magnitude of the annual I-13I releases during the period 1972-1990 generally decreases with a half-life of 2.4 years. The decrease is consistent with the Cf-252 half-life of 2.6 years. The historical I-131 releases lead to the conclusion that I-132, I-133, I-134, and I-135 have also been released to the atmosphere for at least the past 20 years. This conclusion is based on the assumption that historical and current release conditions were similar. If this is the case, the release rates 20 years ago would have been 200 times greater than the current values.

Radioactive isotopes of krypton and xenon must also be released. These noble gases are more volatile and mobile than iodine. The SRTC stack is not monitored for noble gases, and the release rates cannot be calculated because there exist too many variables with unknown values. The noble gases decay to non-gaseous nuclides that deposit in the terrestrial environment. The only daughter nuclide from the noble gases that is predicted to accumulate in the terrestrial environment at measurable levels is Sr-89.

This report documents preliminary findings and includes the recommendation that the release process and the environmental impact of fission products from traces of $\mathrm{Cf}-252$ be thoroughly characterized. The characterization should include:

- additional special measurements to determine the variation of the releases of short-lived isotopes over a longer time period than the two-weel: study reported in this document;

- systematic sampling and analysis for radioiodine at other points : inng the air exhaust pathways to isolate the location and extent of the C.f-2.52 r.or.tamination;

- a study of the sandfilter discharge to determine the level of fission-product noble gas releases;

- a study of the SRTC vicinity to determine if the longer-lived daughter nuclides of $\mathrm{I}, \mathrm{Xe}$, and $\mathrm{Kr}$ are detectable in the local environment;

- an assessment of the dose consequences of the current iodine releases and the noble gas releases and daughter nuclides in the environment, which are to be measured; and

- a complete historical perspective on Cf-252 operations and emission control features with special emphasis on whether the charcoal filter banks are saturated with iodine or a bypass exists.

\section{BACKGROUND}

SKTC inas been the principal suluce of $\mathrm{i}-1 \mathrm{j}$ i released io the atmosphere from SRS since 1988, as shown in figure 1 . This is caused by greatly decreased releases at other facilities after the cessation of reactor operations in 1988 and the subsequent scaling down of reprocessing operations. Releases from SRTC have not decreased correspondingly. SRTC continues to release I-131 at the microcurie level per week. 
The scientists recognized independently the need to identify the source of the I-131 releases. Kantelo becaine aware of the releases while preparing a report of the history of radioiodine at SRS.

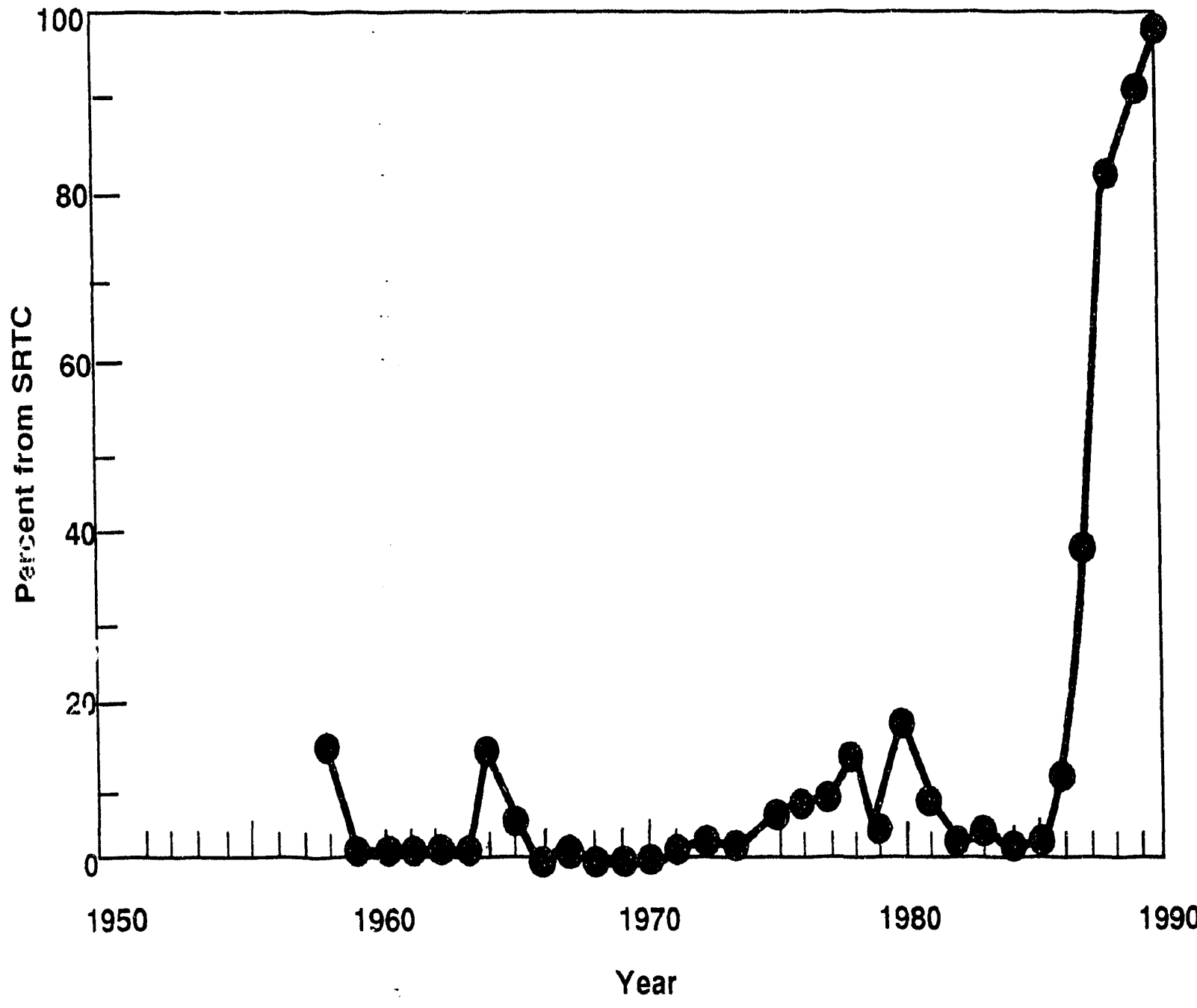

Figure 1 Atmospheric Releases of 1-131: SRTC Compared to Site Total

While verifying routine measurements of weekly charcoal cartridges, Crandall observed that the SRTC sandfilter samples regularly contained low levels of I-131 and intermittently contained low levels of I-133. Mutual interest led to this collaborative study.

To investigate the current releases, special measurements of the existing iodine sampler located at the discharge side of the SRTC sandfilter were conducted. The iodine sampler passes a portion of tive discharged air through a particulate ifitci and thelt ciurough an activatied charcoal cartridge (impregnated with triethylene diamine) to collect iodine. The particulate filter and charcoal cartridge are routinely exposed to the air stream for one week, removed, and analyzed in the laboratory.

The filters and cartridges analyzed in this study were exposed during the periods October 8-15 and 15-22, 1991. Results of the analyses are presented in the Experimental Results section. In the Dis- 
cussion section several scenarios to explain the current and historical radioiodine releases are proposed.

\section{EXPERIMENTAL RESULTS}

The I-131 releases reported for the past 20 years were based on a single gamma spectrometric measurement of each weekly charcoal sample and particulate filter. Typical counting intervals were in the range of 10 to 90 minutes, depending on the type of gamma detector. The large number of samples to analyze precluded longer or repetitive measurements in the Environmental Counting Laboratory of EMS. Typically, the routine samples were measured after a delay of at least three days from the time the cartridge and filter were removed from the air sampler.

To ensure that the short-lived isotopes could be measured in the October samples, the scientists circumvented the normal administrative delays. Doing so allowed gamma measurements to be begun within one hour after the removal time.

The scientists performed repetitive measuremcits ranging from 5 minutes to 17 hours for the charcoal and up to 66 hours for the particulate filter. The measurements were performed using a combination of the gamma spectrometric analysis capabilities of two laboratories-the Environmental Counting Laboratory of EMS and the Ultra Low-Level Counting Facility of the Environmental Technology Section (ETS).

Quantification of releases of sliort-lived nuclides requires special techniques that are not encountered in normal routine analyses of longer-lved nuclides. The details of these techniques and the gamma spectrometric analyses are described in appendix 1.

The measured weekly release rates of radioiodine are shown in table 1 . The overall agreement for the two consecutive sampling periods is excellent. The values for each pair of results agree within the measurement uncertainties, which are at the $95 \%$ confidence level. The tabulated weighted mean weekly release rates were calculated using the reciprocal square of the relative uncertainty as the weighting factor. The tabulated activity ratios relative to I-131 are based on the weighted mean release rates.

\section{Discussion}

Three scenarios are considered to explain the current releases. Other scenarios would be possible if SRS reactors were operating; however, such scenarios have no bearing on the current releases. The scenarios considered are that the radioiodine originates from:

1. traces of unencapsulated Cf-252;

2. fissionable material irradiated at the SRTC Cf-252 Neutron Activation Analysis Facility; and

3. other nuclides that decay by spontaneous fission.

\section{Scenario 1-Traces of Unencapsulated Cf-252.}

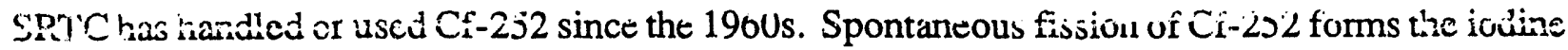
isotopes I-131 through I-135 and other iodine isotopes.

Volatile chemical forms of iodine will diffuse to the laboratory exhaust system if the Cf-252 is not encapsulated. Therefore, traces of unencapsulated $\mathrm{Cf}-252$ are a likely candidate for the origin of the radioiodine. 
Two criteria must be satisfied for the Cf- 252 scenario to be valid. One is that the activity ratio for a given pair of isotopes must be reproducible by calculation using the clinulative yields of the isotopes when formed in Cf-252 fission. The other criterion is that the magnitude of the historical I- 131 atmospheric releases should decrease with the 2.6-year half-life of Cf-252.

The calculation of activity ratio using cumulative fission yields is straightforward if the source is encapsulated. When atoms are removed from the source by volatilization, the release constant, $r$, which is the fraction of atoms volatilized per unit time, must be considered in the calculation. Details of the calculation are provided in appendix 2 .

Table 2, which is a duplicate of table A2-2, summarizes the calculated results. A reasonable fit between calculated and observed activity ratios is obtained with known cumulative fission yields for Cf-252 and a value of $2.5 \mathrm{E}-4$ per second for the release constant. The only anomaly is the poor fit of I-133/I-131, which exhibits a bias of about 40 percent. No error in measurements or calculations can be found to explain the bias.

The calculated activity ratios refer to releases at the source rather than at the indine sampler. Whether there is a difference between the two locations depends on the isotope half-ives and the transit time from the Cf-252 operations areas to the sandfilter discharge. Transit time is estimated to range from three and a half to four minutes (Macmurray,1991).

During the maximum four-minute transit time, the activity of I-134 decreases by five percent due to radioactive decay; the decrease for the other detected isotopess is less than one percent. Given that measurement uncertainties are much greater and the actual lccation of the Cf- 252 is unknown, the effect of transit time is considered to be negligible. For pracical purpuses the measured activities at the sandfilter discharge are equivalent to activities released at the source.

The overall agreement between calculated and observed ratios leads to the conclusion that the first criterion is satisfied.

The second criterion to test the validity of the Cf- 252 scenario is that the magnitude of the historical atmospheric I-131 releases should decrease with the 2.6-year half-life of Cf-252. This is because the release rate of $\mathrm{I}-131$ is proportional to its formation rate in Cf-252. The I-131 formation rate is proportional to the decay rate of Cf-252, which decreases by a factor of two every 2.6 years.

Figure 2 is a graphic display of published I-131 annual releases from SRTC (Cummins, et al. 1991; Hoel, 1991). Only the releases during the period 1972-1990 are tested against the criterion; the yearto-year variations prior to 1972 are excessively large due to the lack of effective emission control. Once a scrubber system was installed at the High Level Caves, radioiodine releases were curtailed; this was determined by special measurements of an iodine sampler exposed to exhaust air (Moyer, 1971).

The dashed line in figure 2 is a statistical fit to the annual releases during the period 1972-1990 (excluding the anomalous data in the period 1986-1988). The slope of the fitted line decreases by a factor of ten in 8.1 years, which is equivalent to a factor of two every 2.4 years. Because this value is consistent with the half-life of Cf-252, the scientists concluded that the annual releases beginning in 1972 are proportional to thic I-131 forluiativin rate in $\mathrm{C}_{1}-252$ and the criterion is satistied. Tile exception is the anomalous releases in the period 1986-1988.

The 1986-1988 releases may be explained by one of the variable circumstances that affect release rates. A number of variable circumstances affects both the release rates and the quantification of the releases. The circumstances that follow may or may not have occurred at any given time during 


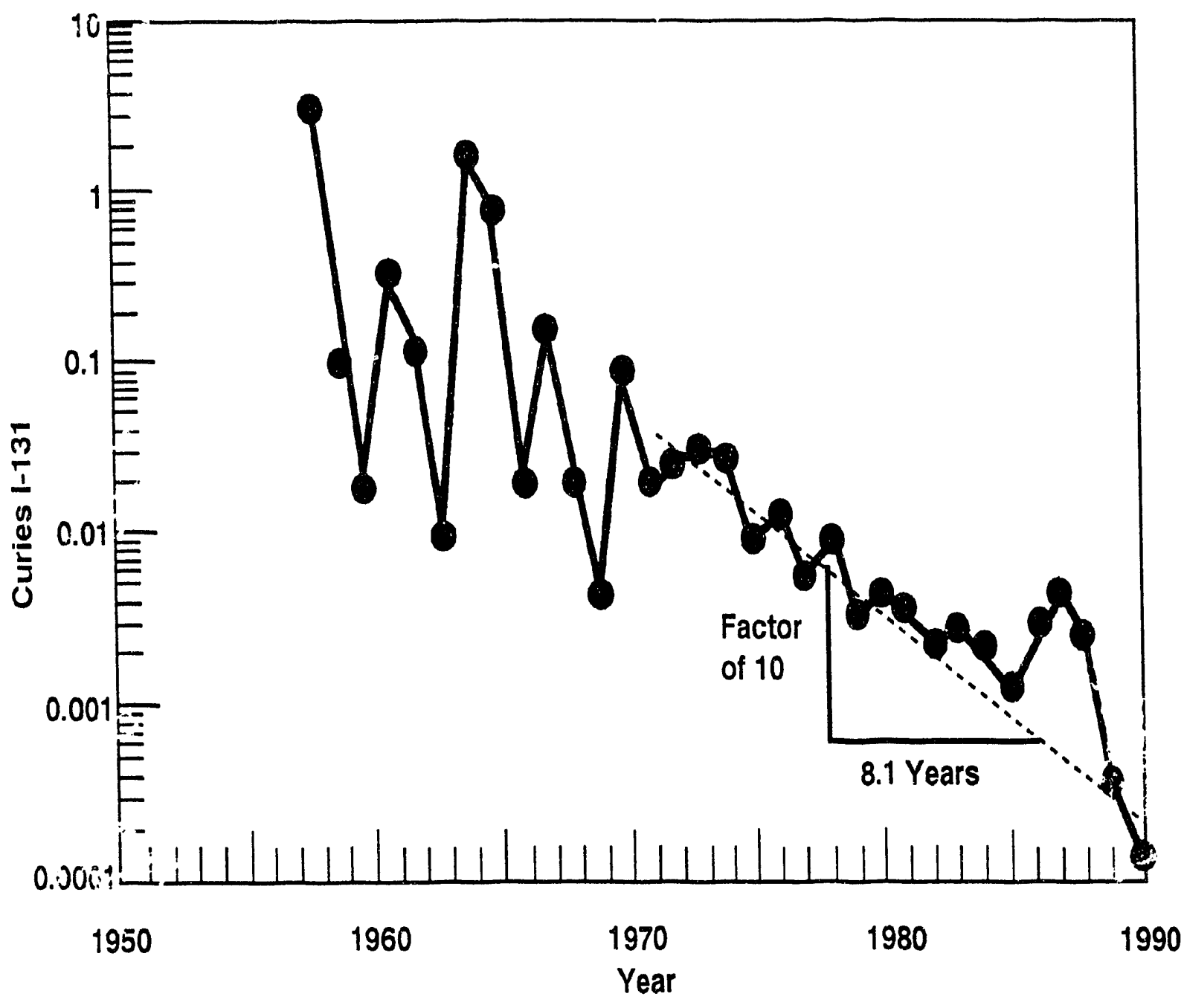

Figure 2 History of Annual SRTC Releases of I-131 to the Atmosphere

M921016.12

the 19 years examined from 1972 to 1990 . Consequently, the criterion regarding the magnitude of the releases is considered to be only a first-order approximation. Circumstances A and B affect the release rates of $\mathrm{I}-131$.

A. The rate of release from the $\mathrm{Cf}-252$ is perturbed by a process other than the decay of Cf-252. For example, modifications to ductwork or equipment can cause abrasion of extraneous particulate $\mathrm{Cf}-252$; this can increase the particulate surface area, which allows indine to diffuse more readily.

B. Chemical processis aite used to prepare new súnices. The quadiiity of iodine volatilized from solution may exceed the quantity volatilized by diffusion. This depends on the oxidation/reduction conditions in solution.

C. Charcoal cartridges are not properly inserted into the iodine samplers. The cartridges contain arrows to indicate the proper orientation for air 
flow. If the cartridge is inserted backwards, the wrong face will be measured in the subsequent labor atory analysis of the exposed cartridge.

D. Charcoal cartridges are not properly placed onto the gamma detector in laboratory analyses. The radioiodine is measured by placing the inlet face of the exposed cartridge on a gamma detector. If the wrong face is measured, the release will be low by a factor of five as discussed in appen$\operatorname{dix} 1$.

E. Charcoal cartridges are not measured in a timely manner after they are removed from the air sampler. This factor depends on the backlog of samples to be analyzed and the availability of operating detectors. If the delay is several weeks, the low levels of I-131 on the sample will have decayed below detection limits.

Circumstance A may have contributcd to the 1983 and 1984 releases, which were slightly greater than predicted. During that time the SRTC irdustrial Cf-252 source fabrication facility was dismantled and transferred to Oak Ridge. The dislodging or abrasion of extraneous particulate Cf-252 during dismantling may have proúliced the slightly greater releases.

Circumstance B may have contributed to the anomalous releases from 1986 to 1988 . New sources of Cf-252 were prepared during the time when I-1.31 releases were as much as ten times greater than predicted by the fitted line in figure 2. Special measurements in 1971 showed that I-131 and I-133 were detectable when operations with Cf-252 occurred in the High Level Caves (Moyer, 1971). "Normal operations" with C.01 i gra:ns of Cf-252 released $1 E 7 \mathrm{pCi}$ of I-131 and 3E7 pCi of I-133. Evaporation of a concentrdted nitric acid solution of 0.007 grams of $\mathrm{Cf}-252$ released 7E8 pCi of I-131 and 2E9 pCi of I-133. Horvever, the installation of a scrubber system curtailed such releases (Moyer, 1971).

Since 1972, charcoal filter banks inave ieen used for control of volatile iodine emissions from the High Level Caves and the Californium Packaging Facility. It is apparent that the source preparation operations in the period 1986-1988 released radioiodine despite the charcoal emission control. An engineering study of the emission control system may reveal the reason for this. It appears that the charcoal may have been saturated or bypassed

When the preparation of sources ceased in 1988, the release rate of $I-131$ returned to its predicted level. The presence of such a "facility background" level may mean that the emission controls have been saturated or bypassed, or the trace contamination of Cf-252 is located downstream of the emission controls. The location of the $\mathrm{Cf}-252$ contamination can be determined by systematic sampling and analysis for radioiodine at various positions along the air exhaust pathway.

Operations with Cf-252 may also have been the origin of I-133 that was released to the atmosphere from SRTC in 1973. That release, whose origin is undocumented, was the only reported annual release of I-133 from SRTC until 1990. The few routine weekly samples that contained detectable I-133 in 1973 and 1990 were probably measured after a shorter time delay than normal. [Special measurements of radioiodine trapped on charcoal during specific operations were taken in the early lu7.3s (Moyer, 1971; Rinehart, 1972)].

The time delay in Circumstance $E$ and the orientation of the cartridge in circumstances $C$ and $D$ are the principal reasons why I-131 is intermittently not detected in a sample. Other factors can cause low levels of radioactivity to not be detected. Examples of such factors are counting techniques, the presence of naturally-occurring radioactivity in the sample, and detector characteristics. 
The detector characteristics include efficiency, resolution, and background. These have steadily improved since the early 1970s as technological advancements enhanced efficiency and resolution and diminished the background. Thus, limitations in detector characteristics are also a reason why I-131 was intermittently not detected.

Scenario 2-Fissionable Material Irradiated at the SRTC Cf-252 Neutron Activation Analysis Facility (NAAF).

Fissionable material may be irradiated to produce radioiodine for use in laboratory experiments or to produce other fission products; in the latter case, radioiodine is a waste product. In either situation some portion of the radioiodine may volatilize to the laboratory exhaust system.

For I-134 (53-minute half-life) to be detected, the radioiodine must be produced at NAAF on the momings the activity was detected; commercial purchase of short-lived isotopes is not an option. No irradiations of fissionable material occurred at NAAF on the mornings of October 15 and 22 (Leyba, 1991). Therefore, this scenario can be rejected.

It should be noted that although this scenario is rejected as the source of the current releases, these conditions may have contributed to the historical I-131 and I-133 releases, especially during the time the production reactors were operating and irradiations were iiot limited to NAAF.

\section{Scenario 3-Other Nuclides That Decay by Spontaneous Fission.}

Spontaneous fission is a rare occurrence in Pu-240, U-235, and U-238, all of which have been used at SRTC. Their half-lives, which are greater than 1000 years, do not correlate with the observed decrease in historical releases. Furthermore, their specific spontanious fission rates are too low to provide the quantity of radioiodine being released. Specific sp'staneous fission rates are approximately 2000 fissions of $\mathrm{Pu}-240$ per minute per gram of weapon: grade plutonium, 0.01 fissions per minute per gram of U-235, and 0.4 fissions per minute per gram of U-238. For comparison, the rate is approximately $4 \mathrm{E} 13$ fissions per minute per gram of $\mathrm{Cf}-252$.

Only Cm-244, with a spontaneous fission rate of $3 E 8$ fissions per minute per gram, can be considered as an altemate to Cf-252. SRTC used significant quantities of Cm-244 during the 1960s.

If $\mathrm{Cm}-244$ were the source of the radioiodine, the same criteria that were tested against $\mathrm{Cf}-252$ would have to be satisfied. With a half-life of 18 years, $\mathrm{Cm}$-244 does not fit the observed 2.4-year half-life for the magnitude of the I-131 releases.

The second criterion is that the activity ratio for a given pair of isotopes must be reproducible by calculation using the cumulative yields of the isotopes when formed in $\mathrm{Cm}-244$ fission. As shown in table 3 , the observed activity ratios cannot be reproduced by calculation using cumulative fission yields and various release constants.

The activity ratios are calculated with the equations developed in appendix 2 , but using the cumulative fission yields for $\mathrm{Cm}-242$. In units of atoms per 100 fissions, these are 2.0 for I-131, 7.4 for I-132, 5.7 for I-133, 6.9 for I-134, and 3.9 for I-135 (Steinberg and Glendenin, 1954). It is assumed that the high-mass yields in the spontaneous fission of Cm-242 and Cm-244 are similar. This is a reasonable assumption because fission systematics show that the shift in cumulative yields of the high-mass fission products are minor for a change of only two mass units in the fissioning nuclide.

Because the criteria are not satisfied, $\mathrm{Cm}-244$ is an unlikely source for the current radioiodine releases. This does not precluade traces of Cm-244 from having been a minor contributor to the historical radioiodine releases. Low-level releases of radioiodine from traces of $\mathrm{Cm}-244$ may be detected in future studies to isolate the location of the traces of Cf-252. 


\section{CONCLUSIONS}

Because Cf- 252 fits both criteria and because other scenarios can be rejected, the scientists conclude that SRTC's atmospheric I-131 releases have originated from traces of unencapsulated Cf-252. Historical data indicate that these releases could have been since 1972.

Given similar release conditions in the earlier years, the short-lived isotopes detected in this study have been released undetected in routine air effluent sampling since the early 1970s. Radioiodine release rates 20 years ago would have been 200 times greater than current release rates.

The minimum mass of $\mathrm{Cf}-252$ that could produce the observed releases is 4 micrograms. The calculation of the mass is based on the release constant of $2.5 \mathrm{E}-4$ per second for iodine and the assumption that all the fission product radioiodine exists in a chemical form that is volatile. If less than 100 percent of the iodine is in a volatile form, a correspondingly greater mass will be required. Details of the caiculation are provided in appendix 2.

As discussed in appendix 2, numerous other iodine fission products are formed in the spontaneviss fission of Cf-252. Their calculated release rates at the source are shown in table 4, which is a duplicate of table A2-4. The weighted means of the weekly releases measured for I-131 through I-135 are included in table 4.

For I-136 through I-142, the activity releases at the source must be distinguished from activity releases to the atmosphere. During the maximum 4-minute transit time, I-137 will decay by a factor rf 1000 and the isotopes I-138 through I-142 will decay by even greater factors. Even if the $C f-252$ contamination is located in the sandfilter, the transit time for the radioisotopes I-136 tlirough 1-142 will still be significant when compared to 2-minutes transit time through the sandfilter?Macmiriray, $199^{1}$ ). In terms of releases to the atmosphere, the releases of I-138 through I-142 are negligible

Fo: uose assessment, only the isotopes I-131 through I-135 need to be considered. The ioduc isotopes are transported through the air by the plume emanating from SRTC's 49-meter stack. They reach the terrestrial environment by deposition from the plume. As the isotopes accumulate in the soil and vegetation, they can enter the food chain.

A preliminary estimate of the dose consequences of the radioiodine releases shows the annual Effective Dose Equivalent for these isotopes is $2 \mathrm{E}-5 \mathrm{mrem}$ for the maximally exposed individual located offsite one km from the SRTC stack (Hamby, 1991). Sixty-seven percent of the dose is due to I-131. The $2 \mathrm{E}-5 \mathrm{mrem}$ is 0.01 percent of the total dose due to all radionuclides released to the atmosphere from SRS during 1990.

Other volatile nuclides, must also be released. Because krypton and xenon are more volatile and mobile than iodine, radioactive isotopes of these noble gases must also be released to the atmosphere. The SRTC stack is not monitored for noble gases. Their releases cannot be calculated because values for many of the factors in the calculation are unknown.

Once released to the atmosphere, the noble gases decay to non-gaseous nuclides. These are also formed from xenon isotopes that result from decay of released iodine. The only daughter nuclide. with potential to be detected in the environmeni is $\mathbf{s r - \hat { y }}$. The subject of noble gas releases is discussed in appendix 3.

A comprehensive characterization of the release process and environmental consequences should be performed. With measured values of the noble gas releases, the dose consequences cain than be assessed not only for iodine but also for the noble gases and their daughter nuclides. 
A related ramification of this study is the consideration that should be given to waste disposal of emission control components. If the High Efficiency Particulate Air (HEPA) filters and charcoal filter banks contain trace Cf-2.52 contamination, they will continue to emit noble gases and iodine when they are removed from service and stored. Furthermore, the charcoal may contain moderately long-lived nuclides that are formed during the time-of-flight through the charcoal filter bank. Such nuclides include Sr-89, Sr-90, Y-90, Y-91, Zr-95, Nb-95, Cs-137, Ba-140, and La-140.

\section{RECOMMENDATIONS}

- The release process and environmental impact of fission products from Cf- 252 should be thoroughly characterized. The characterization should include:

- additional special analyses of the routine samples to determine the variation of the releases of short-lived isotopes over a longer time period than the iwo-week study reported in this document;

- sampling at other points along the air exhaust pathways to isolate the location and extent of the Cf-252 contamination;

- a study of the sandfilter exhaust to determine the level of fissionproduct noble gas releases;

- if nobit: gases are detectable, an environmental study of the SRTC vicinity to determine if the longer-lived daughter nuclides of iodine, xenon, and krypton, e.g., Sr-89, are detectable in the local onsite environment;

- an assessment iry ETS's Environmental Dosimetry Group of the dose consequences of the radioiodine releases, noble gas releases (when determined), and their daughter nuclides in the environment; and

- a complete historical perspective on Cf- 252 operations and emissioncontrol features with special emphasis on whether the charcoal filterbanks are saturated with iodine or a bypass exists.

- Occupational Health Protection and EMS should minimize administrative delays so that measurements of samples can commence sooner than three days after removal from the air stream.

- Personnel involved with handling charcoal cartridges at all SRS locations may be interested to know the reason why their procedures call for a specific orientation of the charcoal cartridge. The wrong orientation will result in a measured release that is reduced by a factor of five. (This recommendation applies to EMS and Health Protection personnel.)

- EMS and Health Protection should consider modification of the cinarcoai cartridge and its holder so that the cartridge can be inserted only in the proper orientation.

- EMS should examine records of 1991 measurements to determine if samples that showed no detectable iodine were counted after a significant time 
delay and/or counted upside down. For example, I-131 releases were below detection limits during the months of March and June of 1991. The count rate of Cs-137 can be used as a guide to determine which face was counted.

- EMS should evaluate two factors that result in reported releases' being greater than actual releases. One is that detector efficiency is calibrated for iodine uniformly distributed throughout the charcoal cartridge. The other is the method to correct for change in the activity of a nuclide during the sample collection interval.

- Occupational Health Protection and Laboratory Services Section should evaluate disposal methods for charcoal filter banks and HEPA filter banks. 


\section{REFERENCES}

Cummins, C. L., C. S. Hetrick, and D. K. Martin, 1991, "Radioactive Releases at the Savarnah River Site 1954-1989," WSRC-RP-91-684, Westinghouse Savannah River Company, Aiken, S.C.

Hamby, D. M., 1991, Personal communication, SRTC Environmental Technology Section.

Hoel, D. D., 1991, "Radioactive Releases-December 1990," ESH-EMS-900030, Westinghouse Savannah River Company, Aiken, S.C.

Leyba, J. D., 1991, "Short Lived Fission Products," memorandum to M. V. Kantelo, October 24, 1991, Westinghouse Savannah River Company, Aiken, S.C.

Macmurray, J. S., 1991, Persor.al communication, SRTC Laboratory Services Section.

Moyer, R. A., 1971, "I-131, 133 Released from B Cell Block, HLC," memorandum to file, October 20, 1971, Technical Division, Savannah River Technolngy Center, E. I. du Pont de Neinours and Company, Aiken, S.C.

Rinehart, W. G., 1972, "Gaseous Fission Products," memorandum to file, March 13, 1972, Technical Division, Savannah River Technology Center, E. I. du Pont de Nemours and Company, Aiken, S.C.

Steinberg, E. P. and L. E. Glendenin, 1954, "Radiochemical Investigation of the Spontaneous Fission of Cm-242," Physical Review 95, 431. 
Table 1. Atmospheric Release Rates of Radiolodine from SRTC to the Atmosphere during Two Weeks In October 1991

Microcurles released per week ${ }^{a}$

\begin{tabular}{|c|c|c|c|c|}
\hline Isotope & October 8-15 & October 15-22 & Welghted Mean & $\begin{array}{c}\text { Actlvity Ratio } \\
\text { to } 1-131^{b}\end{array}$ \\
\hline $\mid-131$ & $0.674 \pm .102$ & $0.638 \pm 084$ & $0.653 \pm .065$ & 1.00 \\
\hline $1-132$ & $53 \pm 12$ & $42.3 \pm 8.9$ & $47.4 \pm 7.4$ & $72.4 \pm 18 \%$ \\
\hline $1-133$ & $9.6 \pm 1.2$ & $9.1 \pm 1.0$ & $9.3 \pm 8$ & $14.2 \pm 13 \%$ \\
\hline $1-134$ & $296 \pm 91$ & $184 \pm 42$ & $224 \pm 41$ & $343 \pm 21 \%$ \\
\hline $1-135$ & $45.9 \pm 7.8$ & $47.2 \pm 5.7$ & $46.8 \pm 4.6$ & $71.6 \pm 14 \%$ \\
\hline
\end{tabular}

a Uncertainty units are absolite and are at the $95 \%$ confidence level ( 1.96 sigma).

b Uncertainty units are ielative as percent and are at the $95 \%$ confidence level(1.96 sigma).

Table 2. Comparison of Observed Activity Ratio with Calculated Activity Ratios for Isotopes Released from Cr-252

Actlvity Ratio

\begin{tabular}{|c|c|c|c|c|c|}
\hline & \multirow{2}{*}{\multicolumn{5}{|c|}{ Calculated for Various ra (Per Second) }} \\
\hline & & & & & \\
\hline & Observed & $r=0.0002$ & $r=0.00025$ & $r=0.0003$ & $r=1$ \\
\hline$|-131 /|-131$ & 1 & 1 & 1 & 1 & 1 \\
\hline$|-132 /|-131$ & 72.5 & 79 & 84 & 88 & 112 \\
\hline$|-133 /|-131$ & 14.2 & 20 & 20 & 20 & 21 \\
\hline$|-134 /|-131$ & 343 & 280 & 313 & 339 & 585 \\
\hline$|-135 /|-131$ & 71.6 & 63 & 64 & 65 & 71 \\
\hline
\end{tabular}

\section{Percent Uncertainty in Observed Ratios}

\begin{tabular}{|c|c|c|}
\hline $\mid-131 / 1-131$ & & 1.00 \\
\hline$|-132 /|-131$ & 8 & 1.09 \\
\hline$|-133 /|-131$ & 13 & 1.40 \\
\hline$i-134,1-131$ & 24 & $0.8 ?$ \\
\hline$|-135 /|-131$ & 14 & 0.87 \\
\hline
\end{tabular}

The Legacy of Cf-252 Operations at Savannah River Technology Center:

Continuous Releases of Radioiodine to the Atmosphere 
Table 3. Comparison of Observed Activity Ratios with Calculated Activity Ratios for $\mathrm{Cm}-242$

\begin{tabular}{lccccc} 
& \multicolumn{5}{c}{ Activlty Ratlo } \\
\cline { 2 - 6 } & Observed & $r=0.0001$ & $r=0.001$ & $r=0.01$ & $r=1$ \\
\hline & 1 & 1 & 1 & 1 & 1 \\
$\mid-131 / 1-131$ & 72.5 & 80 & 134 & 144 & 146 \\
$\mid-132 / 1-131$ & 14.2 & 11 & 12 & 12 & 12 \\
$\mid-133 / 1-131$ & 343 & 112 & 290 & 346 & 353 \\
$\mid-134 / 1-131$ & 71.6 & 21 & 26 & 26 & 26
\end{tabular}

\begin{tabular}{lccccc} 
& $\begin{array}{c}\text { Percent } \\
\text { Uncertainty } \\
\text { In Observed } \\
\text { Ratios }\end{array}$ & \multicolumn{3}{c}{$\begin{array}{c}\text { Ratio of Calculated to Observed Ratios } \\
\text { for Speclfled Values of } \mathbf{r}\end{array}$} \\
\hline $1-131 / 1-131$ & 1.00 & 1.00 & 1.00 & 1.00 \\
$1-132 / 1-131$ & 18 & 1.10 & 1.85 & 1.99 & 2.01 \\
$1-133 / 1-131$ & 13 & 0.80 & 0.86 & 0.87 & 0.87 \\
$\mid-134 / 1-131$ & 21 & $0.3: 3$ & 0.85 & 1.01 & 1.03 \\
$1-135 / 1-131$ & 14 & 0.29 & 0.36 & 0.37 & 0.37
\end{tabular}

a $r=$ release constant for iodine=fraction of volatile lodine atoms removed per unit time. 
Table 4. Summary of Observed and Calculated Volatilization Rates for lodine lsotopes

\begin{tabular}{|c|c|c|}
\hline Isotope & $\begin{array}{l}\text { Microcurles Per Week } \\
\text { Volatllized at Source }\end{array}$ & Half-Ilfe \\
\hline $1-125$ & $6.5 E-14$ & 59.7 days \\
\hline $1-126$ & $9.0 E-12$ & 13 days \\
\hline $1-128$ & $1.1 \mathrm{E}-05$ & $25 \mathrm{~min}$ \\
\hline $1-129$ & $2.5 E-10$ & $1.6 \mathrm{E} 7 \mathrm{yr}$ \\
\hline $\mid-131$ & 0.65 & 8.0 days \\
\hline $1-132$ & 47 & $2.28 \mathrm{hrs}$ \\
\hline $1-133$ & 9 & $20.8 \mathrm{hrs}$ \\
\hline I-134m & 72 & $3.5 \mathrm{~min}$ \\
\hline $1-134$ & 224 & 526 inin \\
\hline $1-135$ & 47 & $6.6 \mathrm{hrs}$ \\
\hline $1-136 m$ & 98 & $46 \mathrm{sec}$ \\
\hline $1-136$ & 213 & $85 \mathrm{sec}$ \\
\hline $\mid-137$ & 292 & $24.5 \mathrm{sec}$ \\
\hline $1-138$ & 193 & $5.53 \mathrm{sec}$ \\
\hline $1-139$ & 69 & $2.38 \mathrm{sec}$ \\
\hline $1-1+v$ & 21 & $0.60 \mathrm{sec}$ \\
\hline 1.141 & 1.1 & $0.4 \% \mathrm{sec}$ \\
\hline $1-142$ & $4.6 \mathrm{E}-02$ & $0.20 \mathrm{sec}$ \\
\hline
\end{tabular}




\section{ApPendix 1. Quantification of Release Rates}

Deiails of the measurement techniques used to identify and quantify the releases of the iodine isotopes are described in this appendix.

To quantify the activity of released short-lived nuclides, two special correction factors must be considered. One pertains to the length of the counting interval and the other to the length of the sample collection interval. These are not normally encountered in routine analyses of longer-lived nuclides.

When measuring the activity in a sample, the average count rate does not occur at the midpoint of the counting interval if the counting interval is a significant fraction of the half-life. This is because the change in activity during the counting interval decreases exponentially rather than linearly with time.

The average count rate will occur at a time that is less than half of the counting interval. The deviation from the midpoint becomes more significant as the ratio of counting interval to half-life increases. When counting interval equals the half-life, the correction is six percent (average count rate occurs at 0.0471 rather than 0.500 times the counting interval). The greatest correction for this study was nine percent when I-134 was counted for 83 minutes ( 1.6 half-lives). Correction factors were taken from the reference (Hoffman and VanCamerik, 1967).

Tha next step is to convert the activity in the sample at the time of the average count rate to activity in the sample at the time of removal from the airstream. This is a simple calculation that corrects for the inange in activity during that time interval. Then the second special correction factor is applied. This :orrects for the change in total activity that occurs during the sample collection interval. As new activity is collected on the sample, older activity is decaying away if its half-life is a significant sactisli of the collection interval.

The collection ci 53 -minute I-134 serves as an example. By the end of the seven-day collection period, any I-134 collected during the first six days and most of the seventh day will have decayed to immeasurably small levels. The activity that is measured immediately after removal of the sample from the air stream represents only the most recently collected activity. Nevertheless, the measured activity can be converted to the total activity collected during the entire sampling interval by the relationship in equation A1-1. The only assumption is that the activity is released and collected at a constant rate.

$$
A=A_{t}\left[\frac{\lambda t}{\left(1-e^{-\lambda t}\right)}\right]
$$

Equation A1-1

where

$$
\begin{aligned}
A= & \text { total activity collected } \\
A_{t}= & \text { artiv di colletvicia } \\
t= & \text { collection time since start of sampling } \\
\lambda= & \text { decay constant, which is the natural logarithm of } 2 \text { divided by half- } \\
& \text { life. The decay constant represents the fraction of atoms decaying per } \\
& \text { unit time. }
\end{aligned}
$$


The correction factor to convert from $A_{t}$ to $A$ is based on the standard equation that relates the activity of a radionuclide and its formation rate. If the formation rate $F$, as atoms per unit time, is a constant during elapsed time $t$, the relationship is

$$
A_{t}=F\left(1-e^{-\lambda t}\right)
$$

\section{Equation A1-2}

(Note that this is a special condition of equation A2-2 in Appendix 2. For the formation rate to be constant during the collection interval, $\lambda_{A}$ in equation A2-2 must be very small; then, the exponential term involving $\lambda_{A} t$ equals 1 . For short-lived nuclides, $\left(\lambda_{B}-\lambda_{A}\right)$ then equals $\lambda_{B}$. These conditions yield equation $\mathrm{Al}-2$.)

The relationship of activity and formation rate is parallel to the activity of an iodine isotope in a charcoal sample and its collection rate. The collection rate is equivalent to the formation rate as long as the coliection rate is constant. This is valid if the release rate is constant and the collection rate is a constant fraction of the exhaust system flow rate.

The total atoms collected during the time interval $t$ is simply the product of the formation rate and the collection time.

$$
\text { Total atoms }=F \times t
$$

The total activity, $A$, that corresponds to the total number of atoms collected is the product of the decay constant and the total number si atorns collected.

$$
A=\lambda \times \text { Total atoms }=\lambda \times F \times t
$$

Equation A1-3

Therefore, from the ratio of equations $\mathrm{A} 1-3$ and $\mathrm{A} 1-2$, the total activity collected is related to the activity at any given collection time by equation $\mathrm{A} 1-1$. For the example of $\mathrm{I}-134$, the total activity collected in seven days is 135 times the activity at the end of collection. The application of this correction factor is discussed in greater detail at the end of this appendix.

The two special correction factors for collection interval and counting interval are applied to the gamma spectrometric measurements that are described in the paragraphs that follow. Several other correction factors that are needed to quantify the activity are also described.

Activity is determined by detecting gamma rays using high-resolution, high-purity germanium detectors. The detected gamma rays are associated with specific nuclides, each of which has a gamma ray signature. The gamma rays and half-lives used to identify and quantify specific iodine isotopes are shown in table A1-1. The tabulated values are contained in the computer code that reduces the counting data. Their accuracy was verified against two standard references (Bowman and Max Murdo, 1974; Ledered and Shirley, 1978).

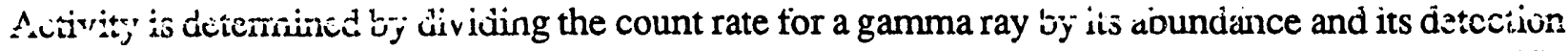
efficiency. The detectors are calibrated for efficiency as a function of gamma energy for specific sample geometries using sources traceable to the National Institute of Standards and Technology.

The calibration source for the geometry of the charcoal cartridge has its standardized activity uniformly distributed throughout the 52-mm height and $75-\mathrm{mm}$ diameter of the cylindrical geometry. 
However, iodine is expected to be non-uniformly distributed in a charcoal sámple. This is because iodine should be trapped during the initial stages of its tortuous path througin the charcoal. If the iodine were uniformly distributed, the charcoal would be saturated and the trapped I-131 would no longer be proportional to the actual release.

The non-uniform distribution of radioiodine results in different count rates for the air inlet and outlet faces of the exposed charcoal cartridge. Figure A1-1 demonstrates that the count rates of the inlet and outlet faces of the cartridge differ by a factor of 4 to 5 depending on gamma energy.

The curve in figure A1-1 represents the ratio for non-coincident gamma rays. It is based on the count rates of the 364- and 529-keV gamma rays from I-131 and I-133 and the 1678-and 1791-keV gamma rays from I-135, which are non-coincident. The 1131- and 1260-keV gammas of I-135 are also used; these are only slightly coincident with other gammas emitted in the decay of I-135.

The ratios plotted in figure A1-1 were determined by decay-correcting measurements to a common time for each week's sample.

The deviation of the two I-132 gamma rays from the curve demonstrites the etfect of summing losses when two high-abundance gamma rays are emitted in coincidence. The ratio of inlet to outlet count rates is less than that expected if the I-132 gamma rays were non-coincident. Coincidence summation losses are significant when measurements are made with the sample close to the detector. The loses are discussed later in greater detail after completing the discussion on the distribution of activity in the charcoal.

To better define the distribution of activity, calibration sources for two ott:e: geometries were measured. One geometry was a cylinder $65 \mathrm{~mm}$ in diameter with standardized activity uniformly distributed in a 4-mm height. The other was a cylinder $75 \mathrm{~mm}$ in diameter with standardized activity uniformly distributed in a $28-\mathrm{mm}$ height. The geometry of the charcoal cartridge is $75 \mathrm{~mm}$ in diameter and $52 \mathrm{~mm}$ high.

Measurements of the additional calibration sources were attempted to rep:oduce the conditions of the inlet and outlet measurements of the actual charcoal cartridges. To duplicate the outlet measurement, the 28-mm-high source was offset from the detector with a spacer so that the top of the source was $562 \mathrm{~mm}$ from the detector face. The 4-mm high source was counted similarly; however, it was not possible to reproduce the geometry of the diameter. The source diameter for the 4-mm high source is $65 \mathrm{~mm}$ compared to $75 \mathrm{~mm}$ for the cartridge.

The calibration sources contained only one non-coincident gamma ray-the $662-\mathrm{keV}$ gamma emitted in the decay of Cs-137. The inlet to outlet ratios for the two sources are compared in figure Al-2 with the non-coincident curve measured for the actual charcoal cartridges.

The results show that the 24-mm high activity layer is too thick to reproduce the ratio of 4 measured for the non-coincident gamma rays. On the other hand, the 4-mm high activity layer is too thin. The ratio of 5 shows that the activity is located too close to the inlet face. The results for the 4-mm high geometry must be considered as onl"' an approximation because the diameter is $65 \mathrm{~mm}$ compared to the $75 \mathrm{~mm}$ of the sample (the diameter of the detector crystal is $70 \mathrm{~mm}$ ).

Tinese comparisüns liwi io the snnclusısn that the iodine activity is contained between the inlet tace and the first approximately $5-10 \mathrm{~mm}$ of the charcoal cartridge. This is illustrated in figure A1-3. The conclusion does not preclude the tailing of low levels of activity deeper into the charcoal.

The true detection efficiency at $662-\mathrm{keV}$ for the charcoal cartridge geometry is intermediate between the efficiencies for the 24- and 4-mm calibration sources, but closer to the efficiency for the 4-mm 
source. The efficiencies at $662-\mathrm{keV}$ for the $24-$ and $4-\mathrm{mm}$ sources are 0.031 and 0.059 gammas detecter per gamma emitted, respectively. The authors estimate the true detector efficiency to be 0.050 gammas detected per gamma emitted.

In reducing counting data, the computer code uses the efficiency determined with the uniformly distributed cailibration source. At $662-\mathrm{keV}$ this efficiency is 0.023 gammas detected per gamma emitted. The ratio of efficiencies, $0.023 / 0.050$, is the factor to correct for the true efficiency in computer-calculated activities. Although the factor is determined only at $662-\mathrm{keV}$, it is assumed to apply to all energies.

Having determined that nearly all activity is located approximately within the first $10-\mathrm{mm}$, the information in figure A1-1 was used to determine the coincidence summation losses for the 668and gammas of I-132.

Coincidence losses for the outlet face measurement are only six percent of the losses for the inlet face. This is because summation coincidence losses are inversely proportional to the product of the efficiencies of the iwo coincident gamma rays (outlet/inlet $=1 /[4 \times 4]$ ).

Consequently, the deviation of the $\mathrm{I}-132$ ratios from the curve in figure $\mathrm{Al}-1$ is a reasonable approximation for the true coincidence summation losses. The authors used the average of the I-132 results to determine a correction factor of 1.37. They also applied this factor to the I-134 results because its two high-abundance gamma rays are also emitted in coincidence and are of similar energy to the I-132 gamma rays.

All the faciors needed to convert count rate to activity are now assembled. The variation of the activity of ic:ine isotopes on the charcoal cartridge as a function of time since removal from the air stradm is shown in figures $\mathrm{A} 1-4$ through $\mathrm{A} 1-7$.

Figures $A:-4$ and $A 1-5$ show that I-134 and I-132 decayed with their characteristic half-lives diring: the s:ve:al iours the authors had custody of the samples immediately after they were removec from the air streain. Tne results in figure A $1-6$ show that the activity of I-131, I-133, and I-135 decays were consistent with their characteristic half-lives. Several days elapsed before the authors had custody again. As expected, only I-131 was detectable in the later measurements shown in figure A1-7. Based on the gamma signatures and the observed decay, there is no doubt about the identity of the isotopes on the charcoal.

The overall uncertainties in figures A1-4 through A1-7 are the counting statistics at the 95 percent confidence level ( 1.96 sigma). To calculate the activity at time of removal from the air stream, other uncertainties were added to each data point by the propagation of errors. These are a six percent uncertainty for the original efficiency, a ten percent uncertainty in the estimated true efficiency, and a 16 percent uncertainty in the correction factor for coincidence summation losses (I-132 and I-134).

The uncertainties other than counting statistics were not included in the plotted data because the purpose of the plots is to show the fit of half-life to the activity data based on counting statistics. The counting statistics are unique to each data point whereas the other uncertainties apply equally to each data point for an isotope.

With all the uncertainties included, each data point was corrected for the change in activity between

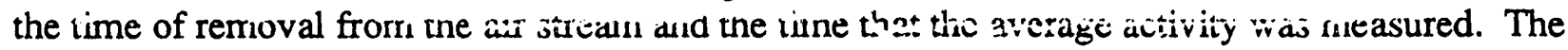
weighted mean of these results determines the activity of an isotope on the charcoal cartridge at removal time. The weighting factor is the reciprocal square of the relative uncertainty.

The charcoal cartridge is only one of two collection media that sample the air stream. A particulate filter precedes the charcoal. No radioiodine was detectable in the filter during a 66-hour measure- 
ment. The detection limit was used to calculate that greater than 99 percent of the I-131 trapped by the sampler was contained on the charcoal. This is consistent with the nature of the release of iodine. Volatile forms of iodine are not expected to be trapped on particulate filters. Consequently, the activity on the charcoal alone is representative of the activity in the air stream.

The activity on the charcoal is corrected for decay during the sample collection interval and adjusted for flow parameters of the sampler and the sandfilter discharge to determine the release rates presented in table 1.

The release rates for I-131 measured in this study will differ from the I-131 release rates reported by EMS for routine analyses of the charcoal filters. The difference results from two correction factors-one for decay during the sample collection interval and the other for the estimated true detector efficiency.

The routine analyses use the efficiency determined by the calibration source that has activity uniformly distributed in a 52-mm heighit. Because the activity is not uniformly distributed in an actual sample, the routinely measured release rates are overestimated by a factor of $2.2(0.050 / 0.023)$. This statement is based on the assumption that the distribution of activity on the sample as determined in these experiments is reproducible in all samples.

EMS has used two techniques to convert I-131 activity measured on the sample to total activity collected. Neither technique uses the rigorous factor (equation A1-1).

The current technique cor rerts the activity back to the midpoint of the collection time. The technique used in recent years prior to 1991 corrected the activity back to the start of the collection interval. These techniques are compar'sd in figure A1-8 to the rigorous correction factor. For a collection interval of one half-life or less, the factor determined by the midpoint technique is reasonably close to the rigorous factor. The frctor determinis by the start-time technique begins to deviate significantly from the rigorous sictor at a coliection time of only 0.2 half-lives.

The deviations from the rigorous facto: are plotted in figure A1-9, which shows the ratio of the midpoint factor to the rigorous factor and the ratio of the start-time factor to the rigorous factor. In the case of I-131, the seven-day collection time corresponds to 0.87 half-lives of I-131. Use of the midpoint technique results in an overestimate of the release rate by a factor of 1.02 , which is negligible. Use of the start-time technique results in an overestimate of the release rate by a factor of 1.4.

The combined effect of these factors is an overestimation of the reported I-131 released in 1991 by a factor of 2.2 (2.2 for efficiency and 1.02 for decay). The overestimation in recent years (prior to 1991 ) is a factor of 3.1 (2.2 for efficiency and 1.4 for decay). These conclusions are based on the assumption that the release rates and collection rates are constant throughout the collection period. The assumption appears to be reasonable for SRTC emissions beginning in the early 1970s. It is probably not valid for releases from the chemical separations areas. Such releases depend on actual reprocessing operations in the canyon buildings.

The method used to correct for decay during collection time has a greater effect on I-133, which has a 20.8-hour half-life. For example, the I-133 releases from SRTC in 1990 were reported on the basis of the start-time sorrestion. The seven-day rollection time correspnnds to 81 half-lives and a fartnr of 270 tor the correction to start time. The rigorous correction factor is 5.6. Thus, the reported releases of I-133 are overestimated by a factor of 106 ( 2.2 for efficiency and 48 for decay).

The information for I-133 applied only to individual samples rather than the reported annual release. The reported annual release is not representative of the true annual I-133 release because I-133 was detected only intermittently while it apparently was continuously released. 


\section{REFERENCES FOR APPENDIX 1.}

Bowman, W. W. and K. W. MacMurdo, 1974, "Radioactive-Decay Gammas," Atomic Data and Nuclear Data Tables 13, 89.

Hoffman, B. W. and S. B. Van Camerik, 1967, "A Table and Method for Determining the True Time Representing a Count Rate Observed in Radionuclear Counting," Analytical Chemistry 39, 1198.

Lederer, C. M. and V. S. Shirley, 1978, "Table of Isotopes," Seventh Edition, John Wiley \& Sons, New York. 
Tablo A1-1. Nuclear Properties Used for Identification and Quantification of lodine Isotopes

\begin{tabular}{|c|c|c|c|}
\hline \multirow[b]{2}{*}{ Isotope } & \multirow[b]{2}{*}{ Half-Llfo } & \multicolumn{2}{|c|}{ Gamma Ray } \\
\hline & & Energy keV & Abundance \\
\hline \multirow[t]{3}{*}{$1-131$} & 8.0 days & 364 & 82 \\
\hline & & 637 & 6.8 \\
\hline & & 284 & 5.4 \\
\hline \multirow[t]{2}{*}{$1-132$} & $2.28 \mathrm{hrs}$ & 668 & 98 \\
\hline & & 773 & 75 \\
\hline$!-133$ & $20.8 \mathrm{hrs}$ & 529 & 87 \\
\hline \multirow[t]{2}{*}{$1-1.34$} & $52.6 \mathrm{~min}$ & 847 & 96 \\
\hline & & 884 & 65 \\
\hline \multirow[t]{4}{*}{$1-135$} & $6.6 \mathrm{hrs}$ & 1260 & 29 \\
\hline & & 1132 & 22 \\
\hline & & 1678 & 9.9 \\
\hline & & 1791 & 7.7 \\
\hline
\end{tabular}

- Gamma rays emitted per 100 decays. 


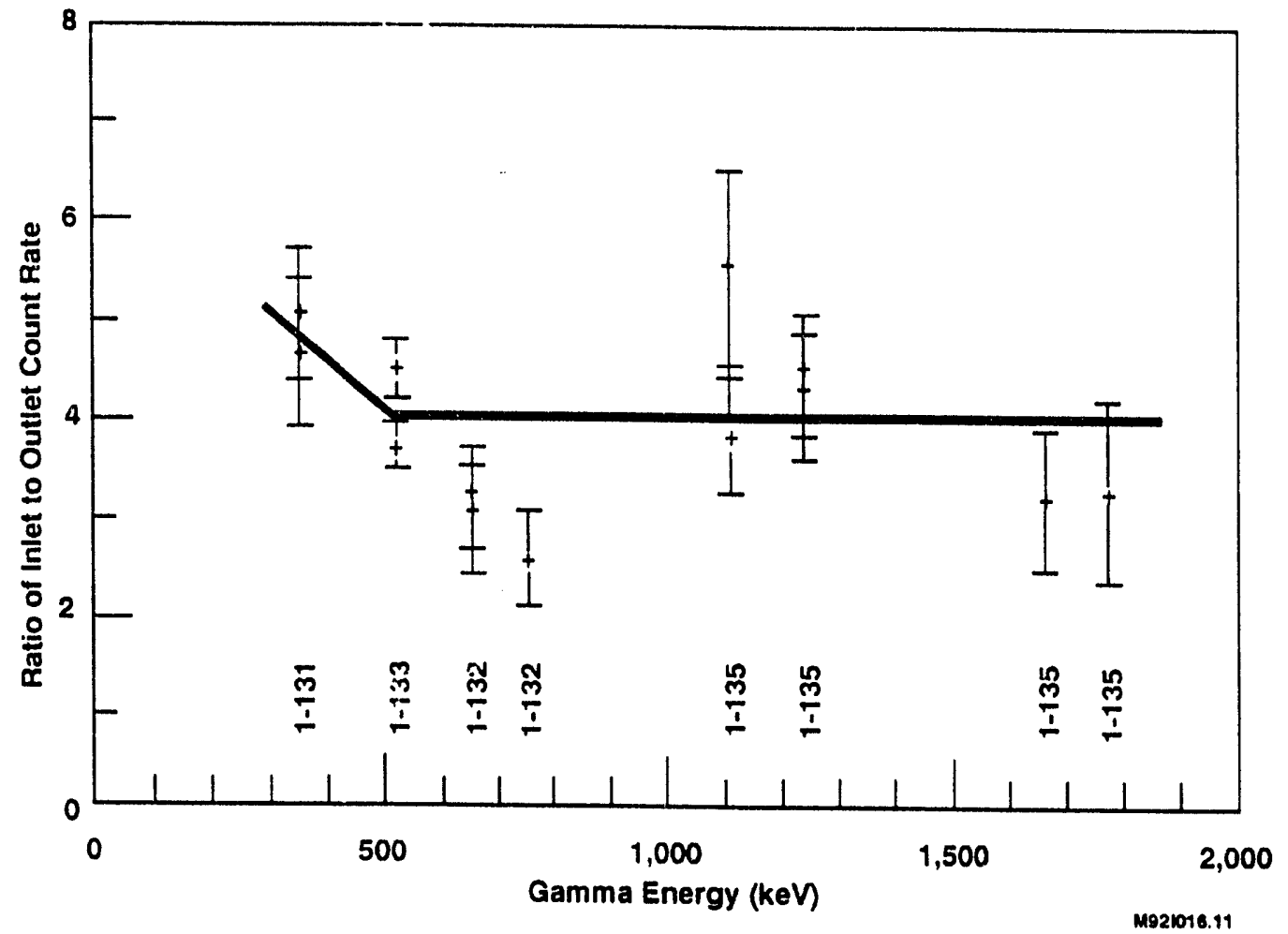

Figure A1-1 Comparison of Count Rates of Inlet and Outlet Faces of Charcoal Cartridge

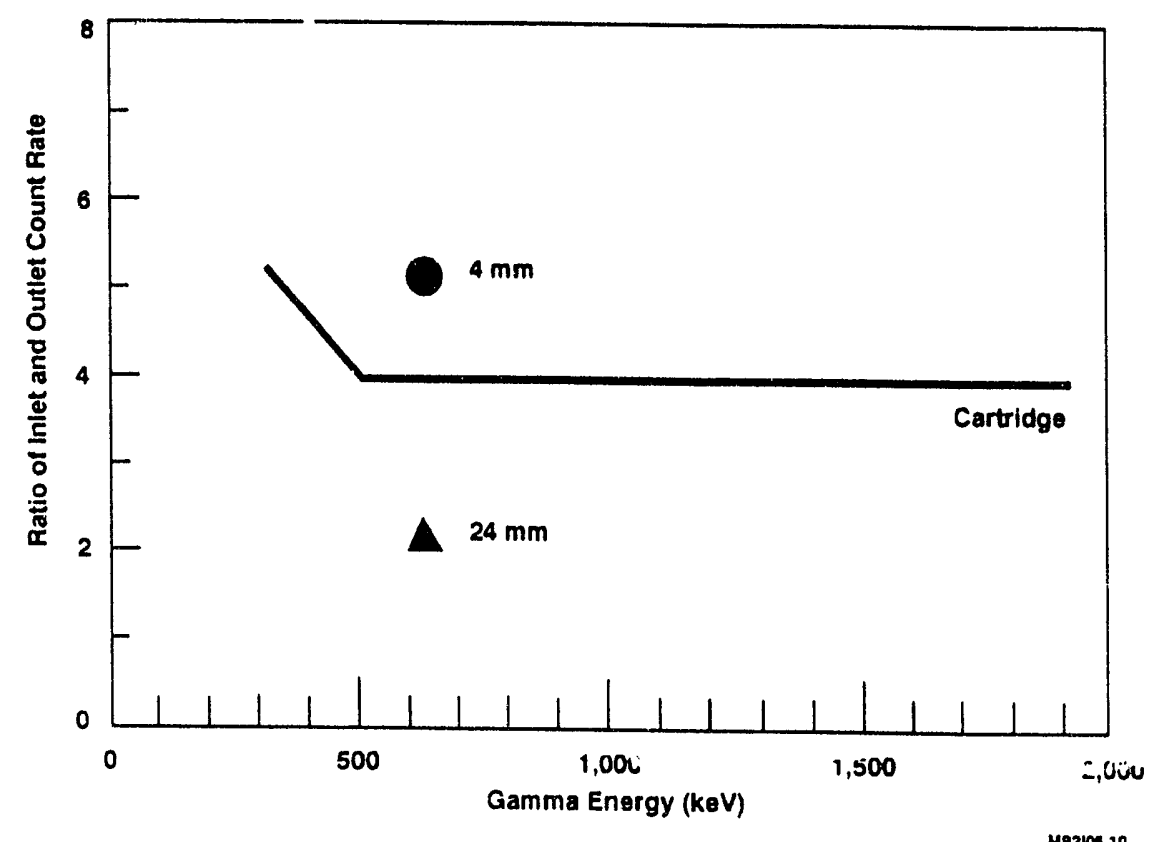

Figure A1-2 I/O Ratios of Various Geometries Compared to the Charcoal Cartridge 


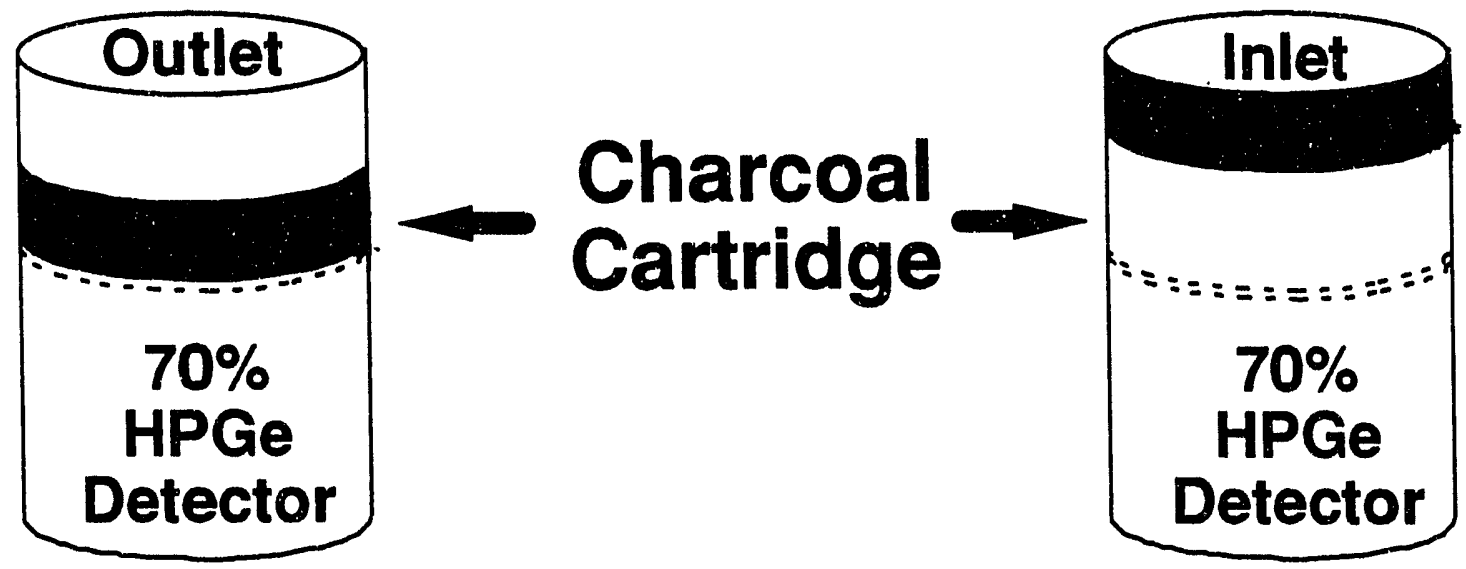

M921016.09

Figure A1-3 Distribution of Activity in Charcoal Cartridge and Illustration of Counting Geometry

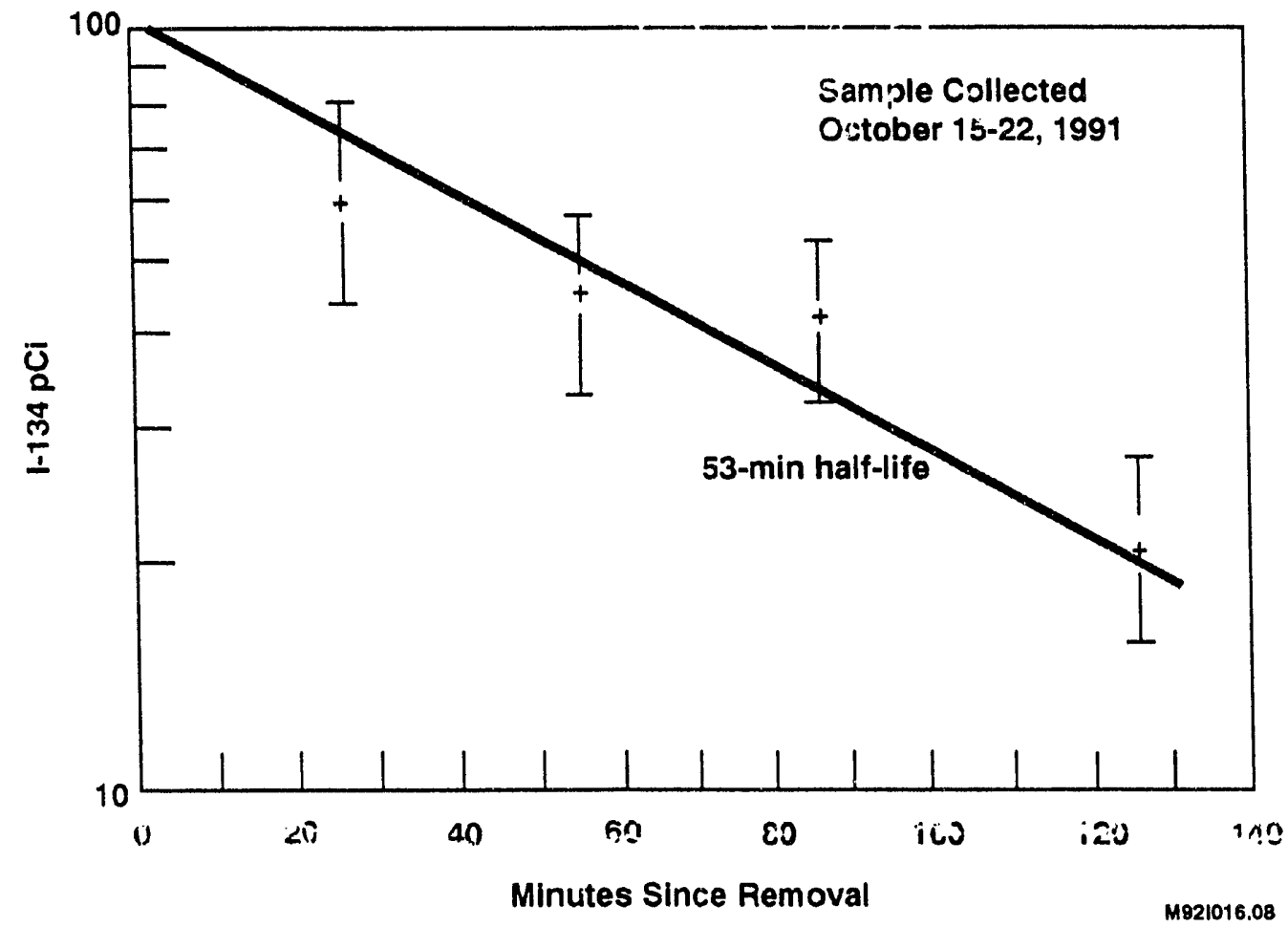

Figure A1-4 I-134 Activity on Charcoal Cartridge After Rernoval from Air Stream 


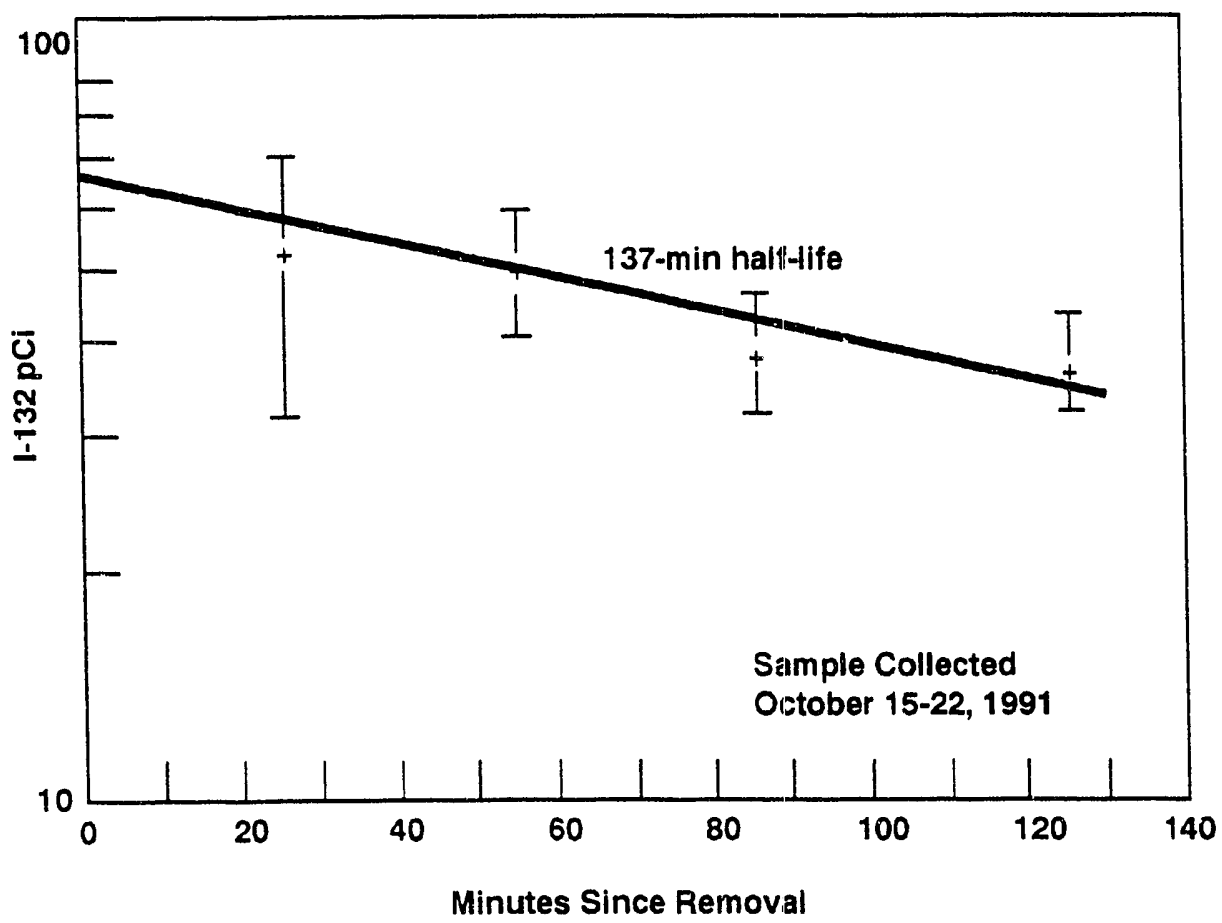

M921016.07

Figure A1-5 I-132 Activity on Charcoal Cartridge After Removal fros. Al: Stream

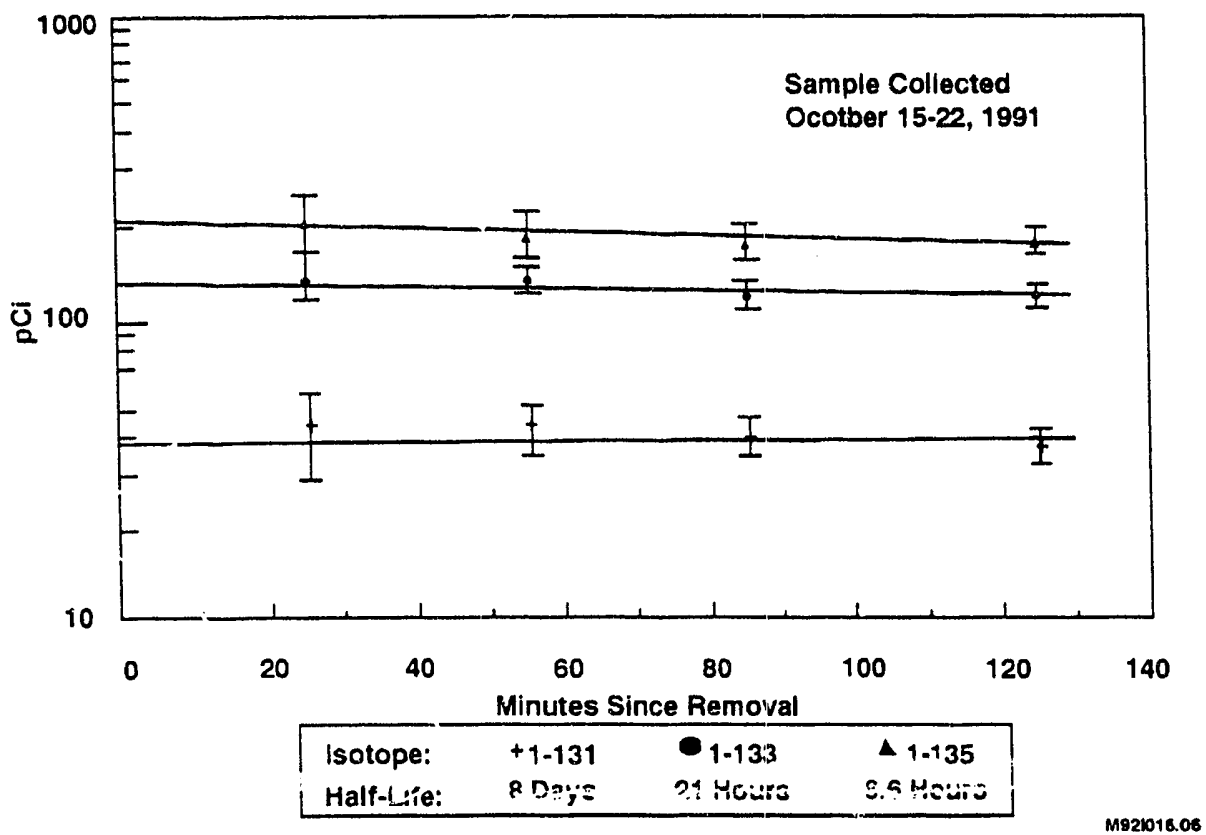

Figure A1-6 Longer-Lived Activity on Charcoal Cartridge After Removal from Air Stream 


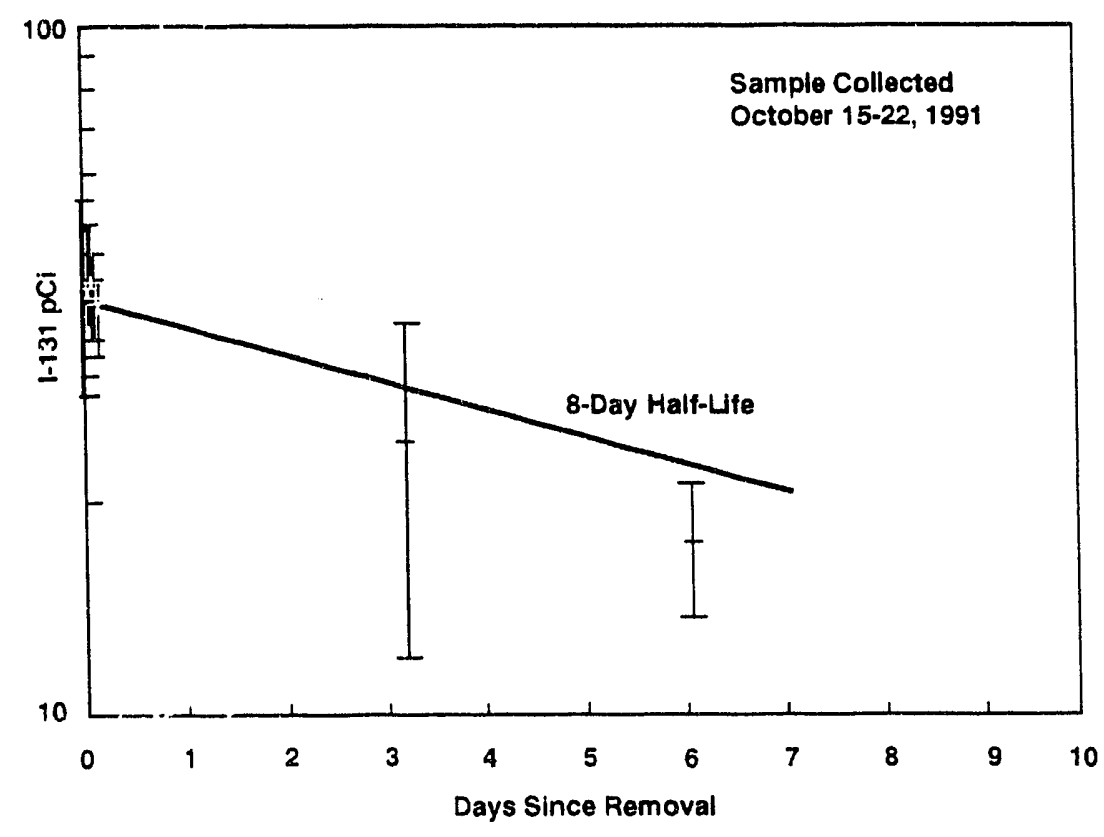

Figure A: - ? 1-131 Activity on Charcoal Cartridge After Removal from Air Stream

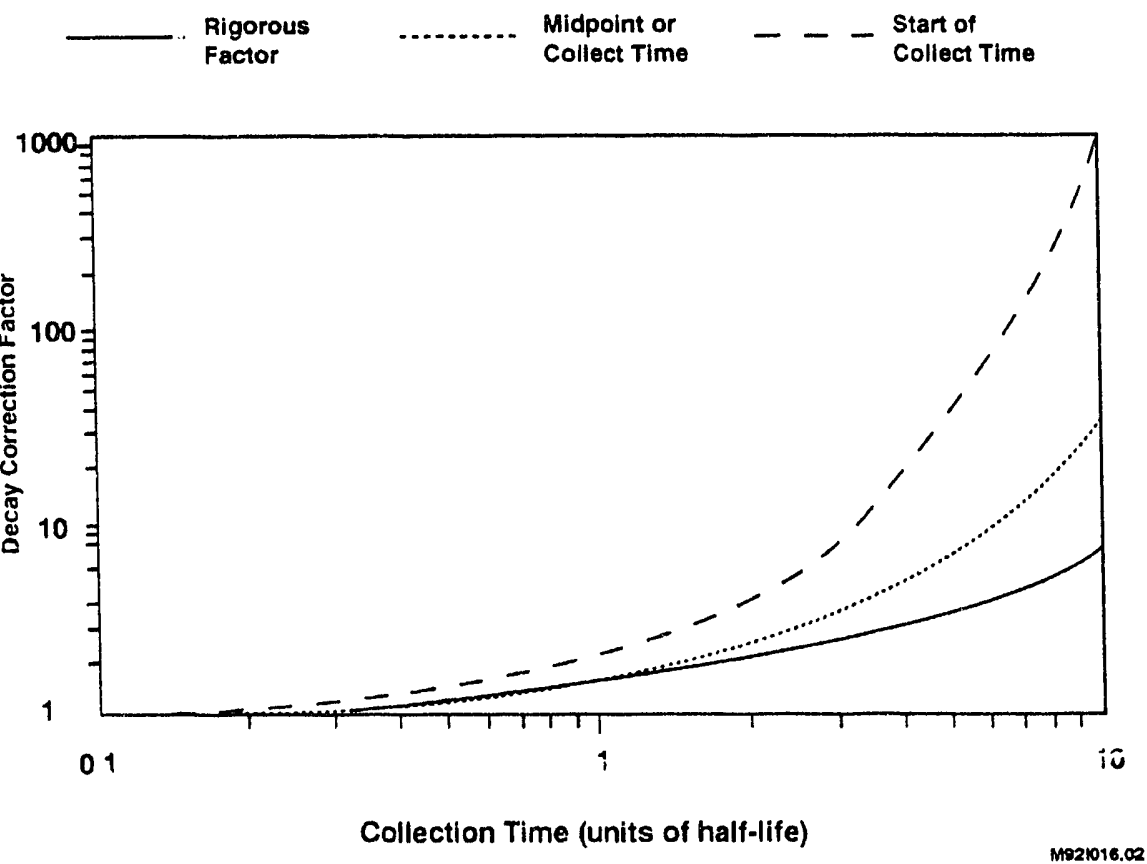

Figure A1-8 Comparison of Factors for Decay During Sample Collection of Constant Release 


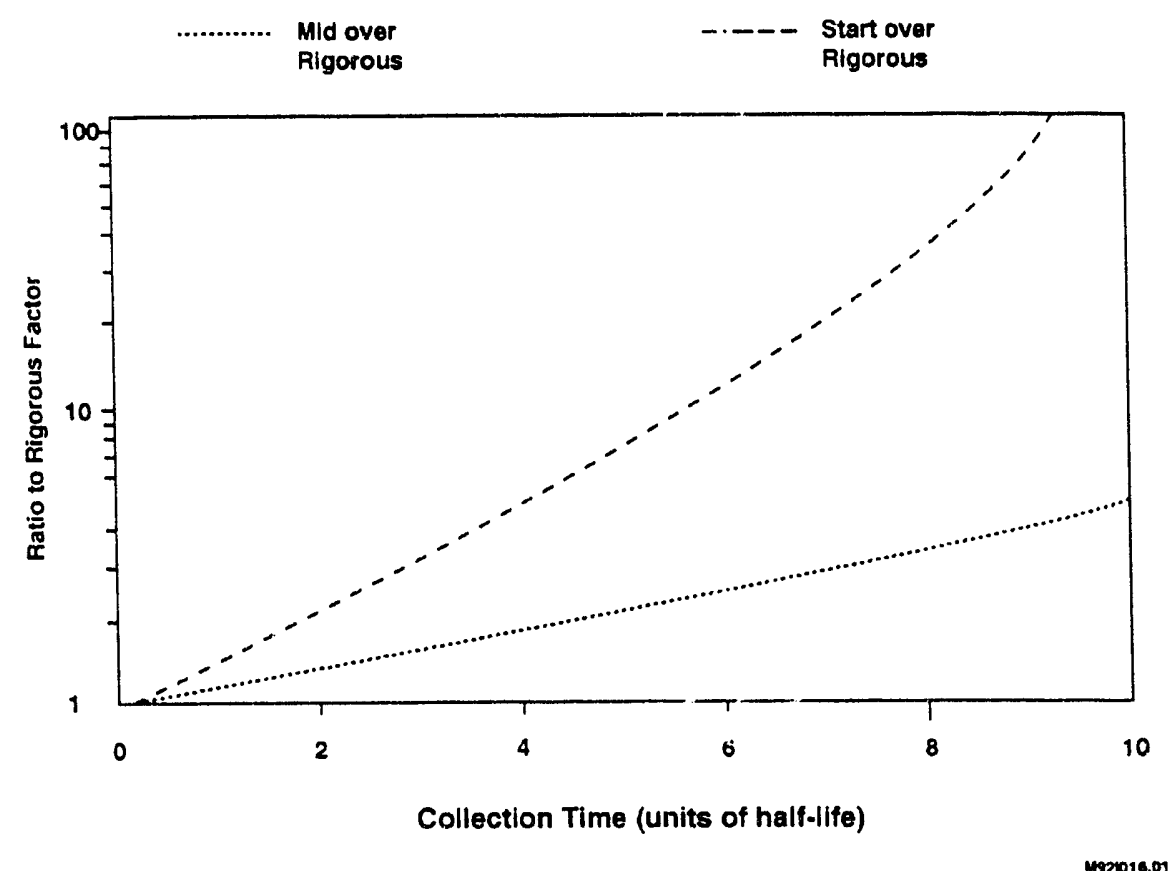

Figure A1-9 Ratios of Factors for Decay During Sample Collection of Constant Release 


\section{Appendix 2. Calculation of Fission Product Ratios and the Quantity of Cf.252 Producing the Releases Radioiodine}

To describe the formation of a fission-product isotope of iodise, general equations are developed from first principles. Then the equations are modified to conform to the more complicated case of spontaneous fission and the volatility of the fission products.

When a genetic relationship exists between a parent and daughter pair of nuclides, the change in the number of daughter atoms with time is the difference between its rate of formation and its rate of depletion. In the common case of a parent-daughter pair with no volatilization, such as Sr-90 and Y-90, the rate of formation of the daughter is equivalent to the decay rate of the parent. The rate of depletion of the daughter is its decay rate. The differential equation relating the rate of change in the number of daughter atoms to the difference between the formation and depletion rates of daughter atoms is

$$
\frac{d N_{b}}{d t}=\lambda_{A} N_{A}-\lambda_{B} N_{B}
$$

\section{Equation A2-1}

where

$$
\begin{aligned}
& N_{B}=\text { atoms of the daughter associated with the parent } \\
& N_{A}=\text { atoms of the parent } \\
& \lambda_{A}=\text { decay constant of the parent (fraction of atoms decaying per unit } \\
& \lambda_{B}=\text { time) }
\end{aligned}
$$

Assuming that no atoms of the daughter exist at time $t=0$, the integrated equation is

$$
N_{B}=\lambda_{A} N_{o A} \times \frac{1}{\left(\lambda_{B}-\lambda_{A}\right)} \times\left(e^{-\lambda_{A} t}-e^{-\lambda_{B} t}\right)
$$

Equation A2-2

where $\lambda_{A} N_{O A}=$ the decay rate of the parent when $t=0$.

Equations A2-1 and A2-2 are based on the formation of one daughter atom for every parent atom that decays. In the case of spontaneous fission, the equations must be modified to account for the following decay conditions: 100 percent of decays do not occur by spontaneous fission and one atom of the specific daughter nuclide of interest is not formed in every spontaneous fission decay.

To correct for these conditions, the term for the decay rate of the parent in the equations must be multiplied by two factors. One, designated SF, corrects for the fraction of decays that occur by spon-

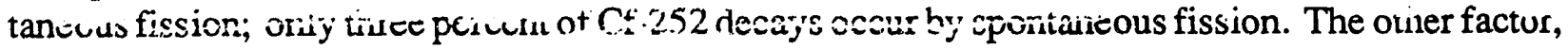
$\mathrm{CfY}$, is the cumulative fission yield of the daughter; only 1.5 percent of $\mathrm{Cf}-252$ spontaneous fission decays form I-131, for example.

When the source is not encapsulated, depletion of the daughter fission products by volatilization must be considered. In case of iodine fission products, not all chemical forms of the element iodine 
are volatile. Thus the parent's decay rate must be multiplied by an additional factor, $\mathrm{C}$, which is the fraction of iodine that is available in volatile chemical forms.

The depletion rate for the volatile daughter atoms consists of both the decay rate and the release rate. The release constant, $r$, is the fraction of atoms that are released by volatilization per unit time from the pool of atoms that exist in volatile chemical form. (The concept of release constant is parallel to the decay constant, which is defined as the fraction of atoms decaying per unit time.)

All these fractions are included in the series of equations that follow. They are developed parallel to equations A2-1 and A2-2, even though the formation of iodine isotopes is typically not as simple as the parent-daughter relationship. An iodine isotope is usually formed as the granddaughter or great-granddaughter in spontaneous fission of $\mathrm{Cf}-252$. Because equilibrium conditions exist, the formation conditions can be simplified to the parent-daughter relationship.

The equation describing the rate of change in the number of daughter atoms that exist in volatile chemical forms is

$$
\frac{d N_{B}}{d t}=S F \times \widetilde{C} F Y_{B} \times C \times \lambda_{A} N_{A}-\lambda_{B} N_{B}-r N_{B}=S F \times C F Y_{B} \times C \times \lambda_{A} N_{A}-\left(\lambda_{B}+r\right) N_{B}
$$

The integrated form of the equation is

$$
N_{B}=\operatorname{si} \times c ? Y_{B} \times C \times \lambda_{A} N_{O A} \times \frac{1}{\left(\lambda_{B}+r-\lambda_{A}\right)} \times\left(e^{-\lambda_{A} t}-e^{-\left(\lambda_{B}+r\right) t}\right) \text { Equation A2-3 }
$$

The release rait of atoms, which is the product of the release constant and the number of daughter atoms that exist in volatile chemical forms, is

$$
r \times N_{B}
$$

The release rate of activity, $V_{B}$, is the product of the decay constant and the release rate of atoms.

$$
\begin{gathered}
V_{B}=\lambda_{B} \times r_{\times} N_{B} \\
V_{B}=S F \times C F Y_{B} \times C \times \lambda_{A} N_{A} \times \frac{\lambda_{B} r}{\left(\lambda_{B}+r-\lambda_{A}\right)}\left(e^{-\lambda_{A} t}-e^{-\left(\lambda_{B}+r\right) t}\right) \quad \text { Equation A2-4 }
\end{gathered}
$$

The activity ratio of two volatilized iodine isotopes, $B 1$ and $B 2$, at the time of volatilization is

$$
\frac{V_{B 1}}{V_{B 1}}=\frac{C F Y_{B 1}}{C F Y_{B 2}} \times \frac{\lambda_{B 1}}{\lambda_{B 2}} \times \frac{\left(\lambda_{B 2}+r-\lambda_{A}\right)}{\left(\lambda_{B 1}+r-\lambda_{A}\right)} \times \frac{\left(e^{-\lambda_{A} t}-e^{-\left(\lambda_{B 1}+r\right) t}\right)}{\left(e-\lambda_{A 2}-e^{\left.-\left(\lambda_{t}+i\right)_{t}\right)}\right.}
$$

Because Cf- 252 has been decaying and forming iodine for the past 20 years, elapsed time is a very large number ( $6 \mathrm{E} 8 \mathrm{seconds)}$. It overwhelms the decay constant for the short-lived isotopes. Consequently, the exponential terms involving $\left(\lambda_{B+r}\right)$ become essentially 0 regardless of the value $c^{f}$ 
The remaining exponential terms then cancel. This leaves the following equation for the activity ratio of two volatilized iodine isotopes.

$$
\frac{V_{B 1}}{V_{B 2}}=\frac{C F Y_{B 1}}{C F Y_{B 2}} \times \frac{\lambda_{B 1}}{\lambda_{B 2}} \times \frac{\left(\lambda_{B 2}+r-\lambda_{A}\right)}{\left(\lambda_{B 1}+r-\lambda_{A}\right)}
$$

Equation A2-6

The half-life of Cf-252 is 2.64 years (Lederer and Shirley, 1978). The decay constant of Cf-252 is $8.32 \mathrm{E}-9$ per second. Other fission yields, half-lives, and decay constants used in subsequent calculations are show in table A2-1. Fission yields and half-lives were taken from the reference (Rider, 1980). All potentially released isotopes are tabulated.

Table A2-2 shows a comparison of the observed activity ratios to the calculated ratios using various values of the release constant, $r$. The lower half of table A2-2 shows the uncertainty in the observed ratios for comparison with the deviations of the calculated values. The uncertainties associated with the calculated ratios are in the range of 10 to 20 percent.

The best fit is obtained with a release constant of $2.5 \mathrm{E}-5$ per second; three of the four calculated ratios are within the uncertainty of the observed ratios. The observed ratio for I-133/1-131 does not fit any of the calculated values. There appears to be a systematic bias of about 40 percent that is unexplainable. No error in the measurements or the calculations can be found.

The change in $r$ of 4 orders of magnitude from 0.0003 to 1 per second does not greatly affect the ratios. The reason for this is seen in the rerm involving $r$ in equation A2-6. As $r$ becomes greater than any of the decay constants, the term approaches 1 and the activity ratio is a function of only the cumulative fission yields and the decay constants. At the other extreme when $r=0$, no volatilization occurs and the decay constants cuncel, whict. leaves the activity ratio as a function of only the ratio of cumulative fission yields (The de:ay corstant for the parent must be negligible relative to the daughters for this to be true.)

The activity ratios calculated for the other iodine isotopes formed by spontaneous fission are shown in table A2-3. A summary of the observed and calculated releases is shown in table A2-4.

The isotopes that have long half-lives or small cumulative fission yields are released in small quantities. Use of equation A2-6 to calculate the releases of isotopes with long half-lives is valid despite the assumption of short half-lives that are used in its derivation. An example is I-129, which has a decay constant of $1.4 \mathrm{E}-15$ per second. Despite the very small value for the decay constant, the exponential term is still essentially 0 because the release constant of $2.5 \mathrm{E}-4$ per second governs the depletion rate.

The greatest release is the very short-lived I-137 (24-second half-life). As half-life decreases to even shorter times for higher mass isotopes, releases would increase correspondingly if it were not for the offsetting effect of rapidly decreasing cumulative fission yield. Consequently, releases actually decrease for the higher mass isotopes.

Transit time from the sonurce to the atmosphere becomes important as the half-life of the releaser isviopis ciecrease. Transit time from the Cf-252 operations facilities is estimated to range from $3 . \mathrm{J}$ to 4 minutes (Macmurray, 1991). This is not significant for the isotopes that were measured.

For I-136 through I-142, however, activity released at the source must be distinguished from activity collected on the iodine sampler at the sandfilter discharge. In a four-minute transit time, I-137 will decay by a factor of 1000 and the isotopes I-138 through I-142 will decay by even greater factors. 
If the traces of Cf-252 are located in the sandfilter instead, the iodine isotopes vvill not have the full transit time to decay by such large factors. However, even if the $\mathrm{Cf}-252$ is located near the beginning of the tortuous path through the sandfilter, the transit time to the sandfilter discharge will still be as much as two minutes (Macmurray, 1991).

The short-lived iodine isotopes decay to radioactive isotopes of xenon. Xenon releases are discussed in appendix 3.

The quantity of trace unencapsulated $\mathrm{Cf}-252$ required to produce the observed radioiodine can be estimated from equation A2-4. Solving the equation for the initial decay rate of the parent gives

$$
\lambda_{A} N_{o A}=\frac{V_{B}\left(\lambda_{B}+r-\lambda_{A}\right)}{S F \times C F Y_{B} \times C \times \lambda_{B} \times r} \times \frac{1}{\left(e^{-\lambda_{A} t}-e^{-\left(\lambda_{B}+r\right) t}\right)}
$$

The release rate of $I-131$ activity, $V_{I-13 I}$, as decays per second released per second, is

$$
V_{I-131}=\frac{0.65 \mu C i}{\text { week }} \times \frac{\text { week }}{6.05 E 5 \mathrm{sec}} \times \frac{1 E 6 \mathrm{pCi}}{\mu C i} \times \frac{2.22 \mathrm{dpm}}{p C i} \times \frac{\mathrm{min}}{60 \mathrm{sec}}=0.040 \mathrm{dps} / \mathrm{sec}
$$

The factor SF is 0.0309 spontaneous fissions per decay (Lederer and Shirley, i.778). The cumulative fission yield of I-131 is 0.0149 atoms per fission. Because the intertst is in the current releases, the time can be represented by $6.05 \mathrm{E}-5$ seconds (seven days).

Substituting $V_{I-131}$ for $V_{B}$ in equation $A 2-7$ gives the initial decary rate of the pisent as

$$
\lambda_{A} N_{o A}=\frac{0.040 \mathrm{dps} / \mathrm{sec}(9.98 E-7+2.5 E-4-8.3 E-9)}{\frac{0.0309 \text { fissions }}{\text { decay }} \times \frac{0.0149 \mathrm{atoms}}{\text { fission }} \times C \times 9.98 E-7 \times 2.5 E-4} \times \frac{1}{(1-0)}=\frac{8.6 E 7}{C}
$$

The number of parent atoms is the decay rate divided by its decay constant.

$$
N_{o A}=\frac{\lambda_{A} N_{o A}}{\hat{\lambda}_{A}}=\frac{8.6 E 7}{C \times 8.3 E 9}=\frac{1.04 E 16 \text { atoms }}{C}
$$

The mass of Cf-252 is

$$
\frac{1.04 E 16 \text { atoms }}{C} \times \frac{\mathrm{mol}}{6.02 E 23 \mathrm{atoms}} \times \frac{252 \mathrm{grams}}{\mathrm{mol}}=\frac{4 E-6 \mathrm{grams}}{C}
$$

Because the value of the factor $C$ is unknown, only an estimate of the mass can be calculated. The minimum mass is four micrograms, which is based on all iodine atoms being in a volatile chemical form. If the fraction of iodine atoms in a volatile chemical form is less than one, a greater mass would be necessary. 
The calculation assumes there is no loss of iodine during the transit time. Thus, the Cf- 252 is assumed to be downstream of the charcoal filter banks for emission control. Also, iodine is assumed not to plate out on the walls of ductwork and sampling lines. Given that iodine has been released for at least 34 years and the sandfilter has been installed for approximately 20 years, all plating sites are assumed to be saturated (stable I-127 is also a fission product).

Isotopic exchange between the currently released iodine and plated iodine may occur. If this were significant, the observed isotopic ratios would be perturbed; I-131, which would likely be the only significant plated activity remaining to revolatilize, would be enhanced relative to the other activities. 


\section{REFERENCES FOR APPENDIX 2}

Lederer, C.M. and V.S. Shirley, 1978, "Tab!e of Isotopes," Seventh Edition, John Wiley \& Sons, New York.

Macmurray, J.S. , 1991, Personal communication, SRTC Laboratory Services Section.

Rider, B.F., 1980, “Compilation of Fission Product Yields,” NEDO-12154-3 (B), General Electric Company, Pleasanton, Calif. 
Table A2-1. Yelds and Decay Properties of lodine Fission Products

\begin{tabular}{|c|c|c|c|c|}
\hline Isotope & $\begin{array}{l}\text { Cumulative Fission } \\
\text { Yield (Atoms Per } 100 \\
\text { Ci-252 Fisslons) }\end{array}$ & Half-llfe & Half-llfe (SeC) & $\begin{array}{l}\text { Decay Constant } \\
\text { (Per Sec) }\end{array}$ \\
\hline$\longdiv { 1 1 2 5 }$ & $1.1 \mathrm{E}-12$ & 59.7 days & $5.16 E+06$ & $1.34 \mathrm{E}-07$ \\
\hline 1126 & 3.3E-11 & 13 days & $1.12 E+06$ & $6.17 E-07$ \\
\hline$i 128$ & $1.5 \mathrm{E}-07$ & $25 \mathrm{~min}$ & $1.50 E+03$ & 4.62E-04 \\
\hline$\lceil 129$ & 0.40 & $1.6 E 7$ yrs. & $4.95 E+14$ & $1.40 E-15$ \\
\hline$i 131$ & 1.49 & 8.0 days & $6.95 E+05$ & $9.98 E-07$ \\
\hline$i 132$ & 1.97 & $2.28 \mathrm{hrs}$ & $8.21 E+03$ & 8.44E-05 \\
\hline$i 133$ & 3.32 & 20.8 hrs. & $7.4 .9 E+04$ & $9.25 E-06$ \\
\hline$i 134 \mathrm{~m}$ & 0.70 & $3.5 \mathrm{~min}$ & $2.10 E+02$ & $3.30 \mathrm{E}-03$ \\
\hline$\lceil 134$ & 3.96 & $52.6 \mathrm{~min}$ & $3.16 \hat{E}+03$ & $2.20 \mathrm{E}-04$ \\
\hline 1135 & 3.64 & $6.6 \mathrm{hrs}$ & $2.38 E+04$ & 2.91E-05 \\
\hline $\mathrm{i} 136 \mathrm{~m}$ & 0.90 & $46 \mathrm{sec}$ & $4.60 E+01$ & 1.51E-02 \\
\hline $1136 g$ & 1.99 & $85 \mathrm{sec}$ & $8.50 E+01$ & $8.15 E-03$ \\
\hline 1137 & 2.67 & $24.5 \mathrm{sec}$ & $2.45 E+0 !$ & 2.83E-02 \\
\hline ¡138 & 1.75 & $6.53 \mathrm{sec}$ & $6.53 E+00$ & 1.06E-01 \\
\hline ¡139 & 0.62 & $2.38 \mathrm{sec}$ & $2.38 \mathrm{E}+00$ & 2.91E-01 \\
\hline$i 140$ & 0.19 & $0.60 \mathrm{sec}$ & $6.00 E \cdot 01$ & 1.16E-00 \\
\hline i141 & $9.9 E-03$ & $0.47 \mathrm{sec}$ & 4.7CE-01 & $1.47 E+00$ \\
\hline$\lceil 142$ & $4.2 E-04$ & $0.20 \mathrm{sec}$ & 2.00E-U1 & $3.46 E+00$ \\
\hline
\end{tabular}

a Fraction of atoms decaying per unit time 
Table A2-2. Comparison of Observed Activity Ratlo with Calculated Activity Ratios for Isotopes Released from Ct-252

\begin{tabular}{|c|c|c|c|c|c|}
\hline & \multicolumn{5}{|c|}{ Actlvity Ratlo } \\
\hline & \multirow[b]{2}{*}{ Observed } & \multicolumn{4}{|c|}{ Calculated for Various $r^{\circ}$ (Per Second) } \\
\hline & & $r=0.0002$ & $r-0.00025$ & $r=0.0003$ & $r=1$ \\
\hline $1131 / 1131$ & 1 & 1 & 1 & 1 & 1 \\
\hline |132/1137 & 72.5 & 79 & 84 & 88 & 112 \\
\hline $\mid 133 / 1131$ & 14.2 & 20 & 20 & 20 & 21 \\
\hline $1134 / 1131$ & 343 & 280 & 313 & 339 & 585 \\
\hline \multirow[t]{2}{*}{$|135 /| 1.31$} & 71.6 & 63 & 64 & 65 & 71 \\
\hline & $\begin{array}{c}\% \text { Unnertainty } \\
\text { In Observed } \\
\text { Ratlos }\end{array}$ & Ratlo of Calc & - Observer & or Speclfle & Les af $\mathrm{r}$ \\
\hline$|131 /| 131$ & & 1.00 & 1.00 & 1.00 & 1.00 \\
\hline $\mid 132 / 1131$ & 18 & 1.09 & 1.16 & 1.21 & 1.54 \\
\hline $\mid 133 / 1131$ & 13 & 1.40 & .41 & 1.42 & 1.46 \\
\hline $1134 / 1131$ & 21 & 0.82 & 0.91 & 0.99 & $1.7 i$ \\
\hline $11: 5 / / 131$ & 14 & 0.87 & 0.90 & 0.91 & $: 00$ \\
\hline
\end{tabular}

a $r=$ release constant for lodinesfraction of volatile lodine atoms removed per unit time. 
Table A2-3. Calculated Activity Ratios for Volatilized Isotopes That Were Not Detected
$|-125 /|-131$
$\mid-126 / 1-131$
$\mid-128 / 1-131$
$|-129 /|-131$
$1-134 \mathrm{~m} / 1-131$
$1-136 \mathrm{~m} / 1-131$
$|-136 /|-131$
$|-137 /|-131$
$\mid-138 / 1-131$
$|-139 /|-131$
$\mid-140 / /-131$
$|-141 /|-131$
$|-142 /|-131$

\section{Activity Ratlo Calculated with $r=0.00025$ Per Second}

$9.98 E-14$
$1.37 \mathrm{E}-11$
$1.64 \mathrm{E}-05$
$3.78 \mathrm{E}-10$
110
149
326
447
295
105
31
1.7
$7.09 \mathrm{E}-02$

Table A2-4. Summary of Observed and Calculated Volatilization Rates for lodine lsolopes

\begin{tabular}{|c|c|c|}
\hline Isotope & $\begin{array}{l}\text { Mlarucuries Per Week } \\
\text { Voiatllized at Source }\end{array}$ & Half-life \\
\hline $1-125$ & $6.5 E-14$ & 59.7 days \\
\hline $\mid-126$ & $9.0 E-12$ & 13 days \\
\hline $1-128$ & 1.1E-05 & $25 \mathrm{~min}$ \\
\hline $1-129$ & $2.5 \mathrm{E}-10$ & $1.6 \mathrm{E} 7 \mathrm{yr}$ \\
\hline $\mid-131$ & 0.65 & 8.0 days \\
\hline $1-132$ & 47 & $2.28 \mathrm{hrs}$ \\
\hline $1-133$ & 9 & $20.8 \mathrm{hrs}$ \\
\hline I-134m & 72 & $3.5 \mathrm{~min}$ \\
\hline $1-134$ & 224 & $52.6 \mathrm{~min}$ \\
\hline $1-135$ & 47 & $6.6 \mathrm{hrs}$ \\
\hline $1-136 m$ & 98 & $46 \mathrm{sec}$ \\
\hline $1-136$ & 213 & $85 \mathrm{sec}$ \\
\hline $1-137$ & 292 & $24.5 \mathrm{sec}$ \\
\hline $1-138$ & 192 & ¿.こs sec. \\
\hline $1-139$ & 69 & $2.38 \mathrm{sec}$ \\
\hline $1-140$ & 21 & $0.60 \mathrm{sec}$ \\
\hline $\mid-141$ & 1.1 & $0.47 \mathrm{sec}$ \\
\hline $1-142$ & 4.6E-02 & $0.20 \mathrm{sec}$ \\
\hline
\end{tabular}




\section{Appendix 3. Noble Gas Releases}

The SRTC atmospheric effluent is not monitored for radioactive isotopes of the noble gases. Fission-product isotopes of xenon and krypton must be released in addition to radioiodine from the Cf- 252 contamination. This is because xenon and krypton are more volatile and mobile than iodine. The sections that follow discuss releases for xenon, krypton, and argon. The releases of most radioactive noble gas isotopes cannot be estimated; too many terms in the release equations have unknown values.

The releases of the radioactive xenon fission-product isotopes that decay to radioactive daughter nuclides are specifically discussed. When formed during the transit time in the SRTC exhaust system, the non-gaseous daughters are filtered from the air stream by the sandfilter.

Many of the radioactive daughters are formed after the parent is released to the atmosphere from the SRTC stack. The decay of the parent then occurs in the plume downwind of SRTC and the daughters eventually deposit in the total environment. The units of radjoactivity used to describe the nuclides in the environment are picocuries (pCi). One million $\mathrm{pCi}$ equal 1 microcurie.

\section{Xenon}

A xenon isotope is formed within Cf-252 fission process in two ways-as the daughter of its parent iodine fission-product isotope and independent of iodine as a direct fission fragment from Cf- 252 . The cumulative fission yield (CFY) of a xenon isotope is the sum of its yields for the independent and genetic pathways. The yield for the genetic pathway is reiated to the CFY of its iodine parent.

When no volatilization of iodine occurs, the yield of a xenon isotope by the genetic pathway equals the product of the CFY for its iodine parent and the frastion of prient decays that produce the daughter (typically 1.0). When volatilization of iodine occurs, an effective CFY must be substituted for the CFY of the iodine parent. The effective CFY for iodine 1sotopes is smaller than the CFY in the case of no volatilization; this is due to depletion of the iodine according to its release constant.

The extent of the perturbation on the CFY for an iodine isotope depends on its decay constant, the iodine release constant, and the fraction of total iodine atoms that are in a volatile chemical form. The latter value, which is designated as $C$ in appendix 2 , is unknown.

The extent of perturbation for only those iodine atoms in the pool of volatile atoms can be determined from equation A2-3. This equation is used because the residual atoms, not the released atoms, decay to produce xenon within the source. For a given iodine isotope, the atom ratio (and activity ratio) of the volatile case compared to no volatilization is the following.

$$
\frac{N_{B} \text { vol }}{N_{B} \text { no vol }}=\frac{\left(\lambda_{B}+0-\lambda_{A}\right)}{\left(\lambda_{B}+r-\lambda_{A}\right)}
$$

The extent of the perturbation is shown in tahle A3-1. The shorter-lived isotopes are unaffected by an iodine release cunsianı or 0.000125 per second. This is because their decay constants overwhelm the release constant. For I-131, however, the effective CFY is only 0.4 percent of the CFY of I- 131 . Because of the eight-day half-life, most I-131 volatilizes before it decays to XE-131 within the source. The perturbations apply only to the atoms in the pool of volatile iodine atoms; the value of $C$ is unknown. 
Two additional unknown factors in the calculation of xenon releases are the release constant for the element xenon and the quantity of xenon released from unencapsulated Cf-252 upstream of the charcoal emission control system.

The release constant for xenon is expected to be greater than iodine's release constant. This is because xenon is more mobile and volatile than iodine. These characteristics result from xenon's chemical nature, which produces only the volatile gaseous chemical form. Thus, the value of $C$ for xenon is 1 .

The other unknown factor is the quantity of unencapsulated Cf-252 located upstream of the charcoal emission control system. The iodine released by such $\mathrm{Cf}-252$ will be trapped by the charcoal, but the xenon will pass through the charcoal.

The remainder of this section on xenon discusses in general terms the releases of the radioactive xenon fission-product isotopes that decay to radioactive daughters. Half-lives and fission yields for the nuclides of interest are shown in table A3-2. Yields are from the references (Rider, 1980).

Because Xe-135 has a long half-life, it decays to Cs-135 principally in the environment. Witin a cwomillion-year half-life, the Cs-135 concentration in the environment will be negligible; every microcurie of Xe-135 released produces $0.0005 \mathrm{pCi}$ of $\mathrm{Cs}-135$. Existing environmental levels of Cs-135 overwhelm the SRTC contribution. The existing levels are principally due to global fallout from atmospheric nuclear weapons testing and the Chernobyl nuclear reactor accident.

The only xenon isotope detected on the charcoal filter was Xe-135. Its activity increased with time, which indicates it was principally present because of ingrowth from its I-135 parent rather thacin trapping of xenon on the charcoal.

Short-lived Xe-137 that is released to the atmosphere will decay to form Cs-137 in thic plume. Be:ause of its 30-year half-life, the Cs-137 concentration in the environment will b: ne gligrible. Every microcurie of Xe-137 produces $0.2 \mathrm{pCi}$ of Cs-137. Similar to Cs-135, existing environmental levels of Cs-137 will overwhelm the SRTC contribution.

The decay of Xe-138 produces Cs-138, which was detected on the charcoal, but not on the particulate filter. This indicates the $\mathrm{Cs}-138$ was formed by decay of $\mathrm{Xe}-138$ during its residence time in passing through the cartridge.

The release rate of $\mathrm{Xe}-138$ can be estimated if it's assumed that no retention of xenon occurs during its passage through the charcoal and that 100 percent of the $\mathrm{Cs}-138$ daughter formed in the cartridge is trapped by the charcoal. The quantity of Cs-138 detected converts to a Xe-138 release rate of $2 \mathrm{E} 7$ microcuries ( 20 curies) per week. A smaller release raie is obtained if xenon is slightly retained by the charcoal; this would lengthen the 0.08 -second residence time that is due solely to the time required for passage. However, charcoal does not retain xenon appreciably at ambient temperatures; this was demonstrated by the ingrowth of $\mathrm{Xe}-135$. In contrast, a greater release rate is obtained if less than 100 percent of Cs-138 is trapped on the charcoal.

Twenty curies of $\mathrm{Xe}-138$ per week is four orders of magnitude greater than the $\mathrm{Xe}-138$ release rate produced from four micrograms of $\mathrm{Cf}-252$. This calculation assumes a release constant for xenon of 0.025 , wivich i: $i 00$ times grealer than wat for iodine. Even if the release cunstant is 0.0025 , ten times greater than that for iodine, the relationship of four orders of magnitude is still valid.

The disparity of four orders of magnitude can result from several factors-the effect on residence time if the transit of xenon is retarded by charcoal, the fraction of total iodine atoms that are in a volatile chemical form, and the quantity of xenon released from unencapsulated Cf-252 upstream 
of the charcoal emission control system. None of the values for these factors are known at this time. This disiassion emphasizes the need to determine the true xenon release rates. Online monitoring for noble gases in the sandfilter discharge should be attempted first. If necessary, techniques with greater sensitivity should be attempted.

Xenon fission-product isotopes heavier than mass 138 have half-lives less than one minute, which means that decay of the isotopes mostly occurs during the transit time before reaching the sandfilter discharge. The longest lived of the heavy xenon isotopes is Xe-139 with a half-life of 40 seconds. It eventually decays to Ba-139. Every microcurie of Xe-139 released produces $8000 \mathrm{pCi}$ of Ba- 139 . No Ba-139 was detected in the charcoal cartridge or particulate filter.

Transit time has an even greater impact on Xe-140, which eventually decays to Ba-140 and La-140. Every microcurie of Xe-140 released produces $12 \mathrm{pCi}$ of Ba-140. Neither Ba-140 nor La-140 was detected in the charcoal cartridge or particulate filter.

Xenon isotopes with mass greater than 140 have half-lives shorter than two seconds and likely are not released from the stack at any significant rate.

Additional radioactive xenon isotopes are formed externally from the traces of Cf-252 contamination. They are formed by the decay of volatilized radioiodine that is transported by the air effluent. Depending on the half-life of the iodine isotope, the fonnation of xenon occurs in the air exhaust system of SRTC or in the environment as the SRTC plums is transported through the atmosphere. The formation of xenon was demenstrated by the Xe-135 activity that increased in the charcoal cartridge after remivval from the air stream.

\section{Krypton}

A krypton isotorie is formed within the Cf- 252 fission process in two ways-as the daughter of its parent bromine fission-produs: isotope and independent of bromine as a direct fission fragment from Cf-252. The CFY of a kry pton isotope is the sum of its yields for the independent and genetic pathways.

Parallel to the case of xenon, the yield for krypton by the genetic pathway is related to the CFY of its bromine parent. Like iodine, bromine atoms can exist in volatile and non-volatile chemical forms. Accordingly, the CFY for krypton must allow for the effective CFY for bromine. Because no bromine was detected on the charcoal cartridge, the effective CFYs cannot be determined.

Two additional unknown factors required for the calculation of krypton releases are the release constant for the element krypton and the quantity of krypton released from unencapsulated Cf-252 upstream of the charcoal emission control system.

The remainder of this section on krypton principally discusses the releases of the radioactive krypton fission-product isotopes that have radioactive daughters. Half-lives and fission yields are shown in table A3-2. The CfYs of radioactive krypton isotopes are a factor of approximately ten smaller than the CfYs of iodine. No krypton isotopes or their daughters were detected in the charcoal cartridge or the particulate filter of the iodine sampler.

With a half-life of 2.8 hours, $\mathrm{Kr}-88$ does not decay significantly during transit to the sandfilter. Most of the $\mathrm{K}_{\mathrm{I}}-88$ decay to short-lived Rb-88 while in thie plume and therefore downyind of the stach.

Short-lived Kr-89 will decay significantly during transit to the sandfilter. Released Kr-89 eventually forms moderately long-lived $\mathrm{Sr}-89$ in the plume. Every microcurie of $\mathrm{Kr}-89$ released produces 40 $\mathrm{pCi}$ of $\mathrm{Sr}-89$. The concentration of $\mathrm{Sr}-89$ in the local environment is not likely to be great enough to be detected, although the level does depend on the quantity of $\mathrm{Kr}-89$ released. The presence of Sr-89 accumulated in the environment can be verified through analyses of local soils. 
Krypton fission-product isotopes heavier than mass 89 have half-lives less than one minute, which means that decay of the isotopes mostly occurs during the transit time before reaching the sandfilter discharge. The longest-lived of the heavy krypton isotope is $\mathrm{Kr}-90$ with a 32-second half-life. Every microcurie of $\mathrm{Kr}-90$ released produces $0.03 \mathrm{pCi}$ of $\mathrm{Sr}-9 \mathrm{C}$ and $\mathrm{Y}-90$. Similar to Cs-135 and Cs-137, existing environmental levels due to global fallout will overwhelm the SRTC contribution.

Transit time has an even greater impact on $\mathrm{Kr}-91$, which eventually forms Y-91. Every microcurie of $\mathrm{Kr}-91$ released forms $0.03 \mathrm{pCi}$ of $\mathrm{Y}-91$.

Heavier krypton isotopes have half-lives less than two seconds and are not likely released from the stack at any significant rate.

\section{Argon}

Neutron activation of the traces of argon present in air forms Ar-41, which has a 1.8-hour half-life. Air passing over unencapsulated or encapsulated Cf-252 will be irradiated by the neutrons produced in the spontaneous fission of Cf-252. Whether the argon in the SRTC exhaust air is sufficiently activated to produce measurable levels of Ar-41 can be determined from the proposed noble gas analyses. 


\section{REFERENCES FOR APPENDIX 3}

Rider, B. F. , 1980, "Compilation of Fission Product Yields," NEDO-12154-3(B), General Electric Company, Pleasanton, Calif. 
Table A3-1. Effective Cumulative Fission Yields of Residual lodine Isotopes

\begin{tabular}{|c|c|c|}
\hline Isotope & $\begin{array}{l}r=0.00025 \\
\text { Correction to Cumulative } \\
\text { Fission Yield }\end{array}$ & $\begin{array}{l}\text { Effective Cumulative } \\
\text { Fission Yleld }\end{array}$ \\
\hline $1-131$ & $3.94 \mathrm{E}-03$ & $5.87 E-03$ \\
\hline $1-133$ & 3.57E-02 & 0.118 \\
\hline $\mid-135$ & $1.04 e-01$ & 0.380 \\
\hline $1-137$ & $9.91 E-01$ & 2.647 \\
\hline $1-138$ & $9.98 E-01$ & 1.746 \\
\hline $1-139$ & 9.99E-01 & 0.621 \\
\hline $1-140$ & $1.00 E+00$ & 0.186 \\
\hline $1-141$ & $1.00 \mathrm{E}+00$ & 0.010 \\
\hline $1-142$ & $1.00 E+00$ & $4.20 E-04$ \\
\hline
\end{tabular}


Table A3-2. Decay Properties and Yields Of Fission-product Xenon and Krypton; Decay Properties of Daughters

Page 1 of 2

Fission Yield (Atoms/100 Fissions)

\begin{tabular}{|c|c|c|c|}
\hline Isotope & Half-life & Independent & Cumulative \\
\hline $\mathrm{Xe-131m}$ & 11.9 days & $2.9 \mathrm{E}-6$ & 0.021 \\
\hline $\mathrm{Xe}-133 \mathrm{~m}$ & 2.2 days & 0.0029 & 0.096 \\
\hline$X e-133$ & 5.2 days & 0.0012 & 3.32 \\
\hline$X e-135$ & $15 \mathrm{~min}$ & 0.206 & 0.741 \\
\hline$X e-135$ & 9.1 hours & 0.085 & 3.94 \\
\hline Cs-135 & 2.3E 6 yrs & & \\
\hline$X e-137$ & $3.8 \mathrm{~min}$ & 2.08 & 4.6 \\
\hline Cs-137 & 30 yrs & & \\
\hline$X e-138$ & $14 \mathrm{~min}$ & 2.85 & 4.62 \\
\hline Cs-138m & $2.9 \mathrm{~min}$ & & \\
\hline Cs-138 & $32 \mathrm{~min}$ & & \\
\hline$X e-139$ & $40 \mathrm{sec}$ & 3.23 & 3.83 \\
\hline Cs-139 & $9.3 \mathrm{~min}$ & & \\
\hline $\mathrm{Ba}-139$ & $1.4 \mathrm{hrs}$ & & \\
\hline $\mathrm{Xe}-140$ & $14 \mathrm{sec}$ & 2.60 & 2.75 \\
\hline Cs-140 & $64 \mathrm{sec}$ & & \\
\hline $\mathrm{Ba}-140$ & 12.8 days & & \\
\hline La-140 & 1.7 days & & \\
\hline $\mathrm{Kr}-83 \mathrm{~m}$ & $1.9 \mathrm{hrs}$ & 7.7E-7 & 0.0586 \\
\hline $\mathrm{Kr}-85 \mathrm{~m}$ & $4.48 \mathrm{hrs}$ & 0.0003 & 0.173 \\
\hline $\mathrm{Kr}-85$ & 10.8 yrs & 0.0013 & 0.0382 \\
\hline $\mathrm{Kr}-87$ & $1.3 \mathrm{hrs}$ & 0.0548 & 0.278 \\
\hline $\mathrm{Kr}-88$ & $2.8 \mathrm{hrs}$ & 0.171 & 0.368 \\
\hline $\mathrm{Rb}-88$ & $18 \mathrm{~min}$ & & \\
\hline $\mathrm{Kr}-89$ & $3.2 \mathrm{~min}$ & 0.251 & 0.350 \\
\hline $\mathrm{Rb}-89$ & $15 \mathrm{~min}$ & & \\
\hline Sr-89 & 50 days & & \\
\hline kr-an & $32 \mathrm{sec}$ & 0.376 & 0419 \\
\hline $\mathrm{Rb}-90 \mathrm{~m}$ & $4.3 \mathrm{~min}$ & & \\
\hline Rb-90 & $2.6 \mathrm{~min}$ & & \\
\hline Sr-90 & 29 yrs & & \\
\hline$Y-90$ & 2.7 days & & \\
\hline
\end{tabular}


Table A3-2. Decay Properties and Yields Of Fission-product Xenon and Krypton; Decay Properties of Daughters

\section{Page 2 of 2}

\begin{tabular}{lccc} 
& & \multicolumn{2}{c}{ Fission Yield (Atoms/100 Fissions) } \\
\cline { 3 - 4 } Isotope & Half-life & Independent & Cumulative \\
\hline Kr-91 & $8.6 \mathrm{sec}$ & 0.259 & 0.270 \\
$\mathrm{Rb}-91$ & $58 \mathrm{sec}$ & & \\
$\mathrm{Sr}-91$ & $9.5 \mathrm{hrs}$ & & \\
$\mathrm{Y}-91$ & 59 days & &
\end{tabular}




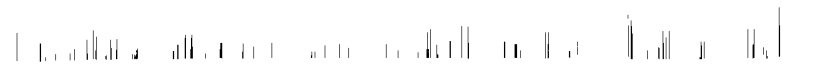
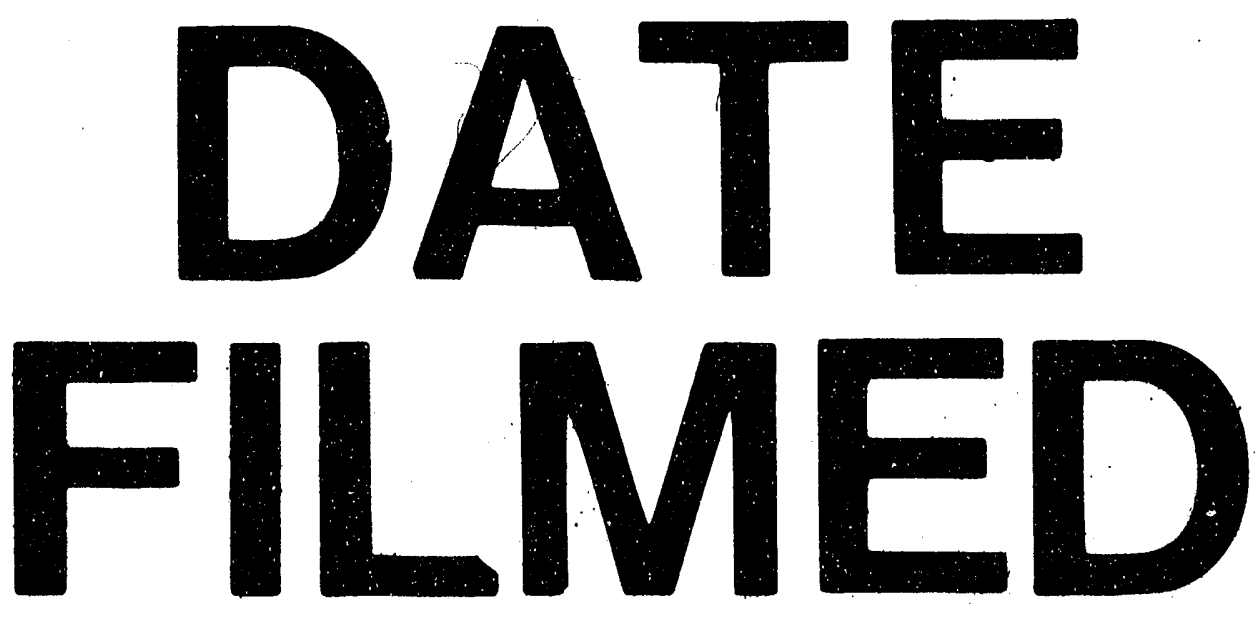

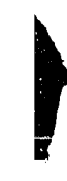

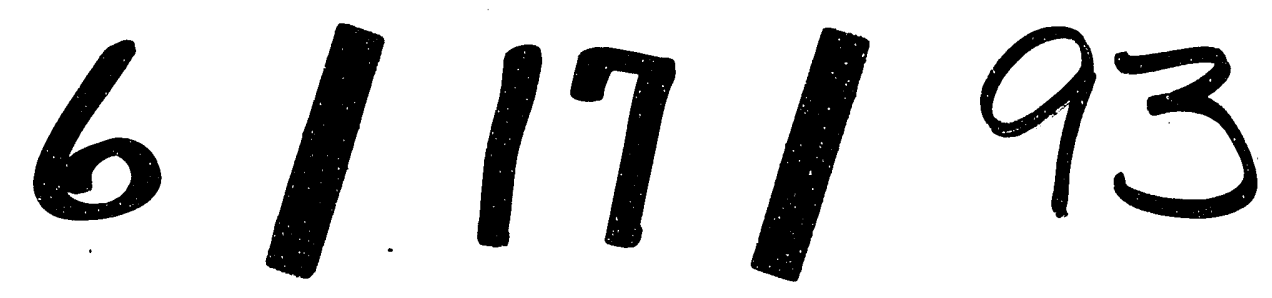




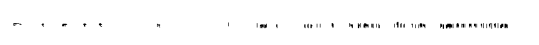

